\title{
Measuring Personal Growth and Development in Context: Evidence of Validity in Educational and Work Settings
}

\author{
Brittney K. Anderson ${ }^{\text {a }}$, John P. Meyer ${ }^{\text {ab }}$, Chelsea Vaters ${ }^{\text {a }}$, \& Jose A. Espinoza ${ }^{\text {a }}$ \\ ${ }^{a}$ Department of Psychology, The University of Western Ontario \\ ${ }^{\mathrm{b}}$ Curtin Business School, Curtin University
}

\section{Corresponding Author:}

Brittney K. Anderson

Department of Psychology

The University of Western Ontario,

London, Ontario, Canada N6A 5C2

Email: bander27@uwo.ca

\section{Acknowledgements:}

This research was supported by research grants from the Social Sciences and Humanities Research Council of Canada (435-2014-0956) awarded to J. P. Meyer. The authors have no conflicts of interest to declare.

\section{Author Notes:}

B. K. Anderson and J.P Meyer equally to this article and both should be considered first authors.

This is the prepublication version of the following manuscript:

Anderson, B.K., Meyer, J.P. Vaters, C., \& Espinoza, J.A. (2019). Measuring personal growth and development in context: Evidence of validity in educational and work settings. Journal of Happiness Studies. https://doi.org/10.1007/s10902-019-00176-w

(C) 2019. This paper is not the copy of record and may not exactly replicate the authoritative document published in the Journal of Happiness Studies. A copy of the on-line version of the article is available at https://rdcu.be/bQ38o 
Measuring Personal Growth and Development in Context: Evidence of Validity in Educational and Work Settings

\begin{abstract}
Consistent with the trend toward viewing psychological well-being as more than the absence of illness, we developed an instrument - the personal growth and development scale (PGDS) - that can be used to assess positive change in well-being attributable to context-specific experiences. As part of the validation process, we examined relations between the PGDS and measures of need satisfaction and autonomous motivation in students $(\mathrm{N}=241)$ and employees $(\mathrm{N}=468)$. In the student sample, we also examined relations with engagement and burnout. The findings supported our hypothesis that need satisfaction, autonomous motivation and engagement would relate positively with the PGDS, and that burnout would relate negatively. In a second student sample $(\mathrm{N}=377)$, we collected longitudinal data to investigate how global psychological wellbeing relates to personal growth and development over the course of an academic term. We found that initial levels of global well-being predicted positive changes in growth and development - the rich get richer - and replicated earlier findings regarding relations between the PGDS, need satisfaction and autonomous motivation. Future applications of the PGDS for research and practice are discussed.
\end{abstract}

Key words: personal growth and development; psychological well-being; eudaimonic wellbeing; self-determination theory; job-demands resources theory 


\section{Measuring Personal Growth and Development in Context: Evidence of Validity in Educational and Work Settings}

With the advent of the positive psychology movement at the turn of the millennium (Seligman \& Csikszentmihalyi, 2000), there has been an increasing tendency to view mental health as more than the absence of illness (e.g., stress, burnout). One clear illustration of this trend is recent theory and research pertaining to eudaimonic well-being (Ryan, Huta, \& Deci, 2008; Waterman, 2013). Although there is no consensus on a precise definition, eudaimonic well-being is commonly conceptualized as a healthy state of living where individuals are free to discover and express their true selves and work toward the realization of their full potential (Ryff, 2014; Waterman \& Schwartz, 2013). Among the most widely used measures in this tradition have been Waterman and colleagues' (2010) Questionnaire for Eudaimonic Well-being (QEWB) and Ryff's (1989) Scales of Psychological Well-being (SPWB).

With this shift to a more positive psychology, several theories of well-being have been developed or evolved to embrace positive mental health as a desired end state. Two examples of particular relevance to the present research are self-determination theory (SDT; Deci \& Ryan, 1985; 2000) and the job demands-resources (JD-R) model (Schaufeli \& Bakker, 2004). According to SDT, an individual's psychological well-being rests on the satisfaction of three core needs (autonomy, competence, and relatedness) and the experience of autonomous (vs. controlled) motivation. Although SDT predates the positive psychology movement, there has been increasing emphasis on its compatibility with eudaimonic philosophy and relevance to understanding and promoting positive mental health (Ryan, Curren, \& Deci, 2013). Similarly, the JD-R model has expanded from its early focus on the causes and consequences of burnout to include the causes and consequences of engagement. Among the potential consequences of engagement is positive psychological well-being (Schaufeli \& Taris, 2014).

Despite this re-focusing, much of the research pertaining to SDT, the JD-R model, and related theories continues to rely on measures of psychological distress (e.g., anxiety, stress) as outcomes. This may be due, in part, to the lack of appropriate positive outcome measures. That is, while there are measures to assess the degree to which individuals feel anxious or stressed within a particular context (e.g., at school or work), there are no comparable measures of the extent to which these contexts contribute to positive psychological well-being. The QEWB and SPWB measure well-being as a stable state, or lifestyle, that is not amenable to the investigation of changes in eudaimonic or psychological well-being resulting from context-specific experiences, particularly in the short- or medium-term. Other measures that have been used, such as vitality (e.g., Deng, Guyer, \& Ware, 2015), flourishing (Diener et al., 2010), or thriving (Porath, Spreitzer, Gibson, \& Garnett, 2012), also tend to be quite general and responses are not easily attributable to the conditions under investigation (e.g., education or work).

To elaborate by way of analogy, consider a comparable situation involving satisfaction. A researcher might be interested in knowing whether a particular policy or practice contributes to greater employee satisfaction. If he/she was to measure 'satisfaction with life', it is unlikely that a relationship would be found because there are too many other factors contributing to life satisfaction. Similarly, if a practitioner wanted to know if a particular intervention had an effect on employee satisfaction, he/she would also likely find a life satisfaction measure to be insensitive. In contrast, a measure of job satisfaction might be expected to show an effect. Therefore, the primary objective of the present research was to develop a measure of personal growth and development that can be used in research and practice to assess the degree to which context-specific experiences contribute to perceptions of positive change in well-being. Such a measure would be useful in addressing research questions such as "Does condition $\mathrm{X}$

or practice Y contribute to employees' positive growth and development?" It would also serve as a useful, practical tool to aid organizations in evaluating whether employees view their work as contributing to their growth and development.

A second objective of the research was to investigate the relations between the new personal growth and development scale (PGDS) and key variables from SDT (need satisfaction and autonomous motivation) and the JD-R model (engagement and burnout). These variables served as the "nomological network' (Cronbach \& Meehl, 1955) used for purposes of validating the PGDS. However, the findings 
also serve a substantive purpose by demonstrating how the PGDS can be incorporated as an outcome measure in these theories consistent with their revised emphasis on positive psychological outcomes.

Although there are various models and measures of eudaimonic well-being (see Waterman, 2013), the present research was guided primarily by Ryff's (1989) model of psychological well-being. Consequently, we use the term psychological well-being in lieu of eudaimonic well-being hereafter. A final objective of our research was to investigate how global well-being, as reflected in Ryff's SPWB, relates over time to the PGDS as a measure of growth and development attributable to context-specific experiences. Again, the findings have relevance for the construct (convergent and discriminant) validity of the PGDS and are also of substantive interest.

\section{Ryff's Model and Measures of Psychological Well-being}

Ryff (1989) introduced her model of psychological well-being to address the lack of attention being paid in the 1980s to positive human functioning (Ryff, 2014). The model had its roots in Aristotelian philosophy (Aristotle, trans. 1985) and was intended to integrate concepts from existential and humanistic psychology (e.g., Allport, 1961; Maslow, 1968) to capture the essence of psychological well-being (Ryan \& Deci, 2001; Ryan et al., 2008). According to Ryff and her colleagues (Ryff, 1989; Ryff \& Keyes, 1995; Ryff \& Singer, 2006), psychological well-being is a multidimensional construct with six distinguishable components: autonomy (living according to personal convictions), environmental mastery (effective management of life situations), personal growth (making use of personal talents and potential), positive relations (deep connections with significant others), purpose in life (sense of meaning, purpose and direction), and self-acceptance (knowledge and acceptance of self). The scales developed to measure these components each included 20 items (Ryff, 1989), but shorter versions with 14, 9, 7, and 3 items have also been used (see Ryff, 2014).

There has been debate about the dimensionality of Ryff's SPWB, with some investigators providing evidence for six factors (Ryff, 1989; Ryff \& Keyes, 1995) and others for a single factor (Kafka \& Kozma, 2002) or a higher-order factor (van Dierendonck, 2004). Even when a 6-factor model provides a superior fit, the dimensions tend to be highly correlated (Springer \& Hauser, 2006). Using a more advanced exploratory structural equation modeling (ESEM) approach, Espinoza, Meyer, Anderson, Vaters, and Politis (2018) found support for a bifactor model in which a global factor accounted for a substantial portion of the variance in most items. The evidence for a single underlying factor suggests that a composite measure can be meaningful, and indeed such a measure has been used in numerous studies (e.g., Schleicher et al., 2005; Shapiro \& Keyes, 2008). Therefore, for present purposes, we treat psychological well-being as a unidimensional construct (i.e., as reflected in the SPWB global factor).

Although Ryff's (1989) SPWB have been used as outcome measures in various studies, including intervention studies (e.g., Ruini, Belaise, Brombin, Caffo, \& Fava, 2006), they measure quite stable constructs. Consider, for example, the following items: "My decisions are usually not influenced by what everyone else is doing" (Autonomy); "In general, I feel I am in charge of the situation in which I live" (Environmental Mastery). These statements reflect a relatively stable state of being that is likely to have evolved over time. Any changes in these conditions are also likely to require time and be the result of multiple influences. Consequently, the SPWB are not ideally suited to measuring the impact of contextspecific experiences, like those at work or university, on changes in psychological well-being. Therefore, our objective was to develop such a measure.

\section{Development and Validation of the PGDS}

Development of the PGDS was based on Ryff's (1989) theory but deviated in several respects. First, rather than taking a multidimensional perspective, we sought to develop a unidimensional measure. This decision was based on our desire to develop a relatively short measure, as well as evidence that the subscales of the SPWB are highly correlated (Springer \& Hauser, 2006) with much of the variance explained by a global factor (Espinoza et al., 2018). Therefore, we treated Ryff's dimensions as reflecting

content domains to be captured within our unidimensional measure. Second, we included only five of Ryff's six content domains. We did not include items pertaining the personal growth domain because the PGDS itself was intended to measure personal growth and development in general. Finally, we revised 
the definitions of the remaining five content domains to be more compatible with our objectives (see the Preliminary Scale Development section below for details).

We took a construct-oriented approach to the development and validation of the PGDS following procedures outlined by Hinkin (1998). Guided by the content domain definitions, subject matter experts wrote and screened items to generate a 15-item PGDS, which we then administered to students and employees in our main study. These data were used to evaluate the dimensionality of the PGDS and to test for measurement equivalence across samples and time. Along with the PGDS, we also administered other measures of well-being, including Ryff's (1989) SPWB (students only), and measures of several key variables from SDT and the JD-R model to aid in the validation process. Brief descriptions of SDT and the JD-R model, and their relevance to validation of the PGDS, are provided below.

\section{Self-Determination Theory}

According to SDT, individuals seek to satisfy three innate psychological needs: autonomy (volition and self-endorsement of behavior), competence (self-efficacy and self-control), and relatedness (social significance and connection). Moreover, the satisfaction or thwarting of these needs within a given context will have implications for the strength and nature of an individual's motivation. When their needs are satisfied, individuals are more likely to engage in a task out of enjoyment (intrinsic motivation), or because they see it as compatible with their core values (identified regulation). Both intrinsic motivation and identified regulation are considered forms of autonomous motivation and have been linked to higher levels of performance and well-being in various contexts, including education (Reeve, 2002) and work (Gagné \& Deci, 2005). In contrast, when individuals feel controlled due to external contingencies (extrinsic regulation: material or social) their need for autonomy might be thwarted, thereby undermining well-being and leading to restriction of performance to meet minimum standards (Deci \& Ryan, 2014).

Despite its links to eudaimonic philosophy and relevance to positive mental health (Ryan et al., 2013), much of SDT research involves psychological distress as an outcome (e.g., Parker, Jimmieson, \& Amiot, 2010). A few studies have included measures of thriving or vitality (e.g., Benedetti, Diefendorff, Gabriel, \& Chandler, 2015) but, as noted earlier, these measures also tend to reflect global, relatively stable well-being and are not well-suited to detecting improvements in psychological well-being resulting from experiences within a specific context. The PGDS was developed specifically with applications such as this in mind. According to SDT, individuals who have their needs satisfied and are autonomously motivated (versus externally regulated) within a particular context (e.g. school or work) should experience a sense of personal growth and development.

\section{Job-Demands Resources Model}

The JD-R model was developed by Demerouti, Bakker, Nachreiner, and Schaufeli (2001) to advance earlier models of stress and burnout (e.g., Karasek, 1979; Siegrist, 1996) by including a wider array of contributing factors (demands and resources). It has since evolved to include engagement as an antipode to burnout, presumably with more positive mental health outcomes (Schaufeli \& Bakker, 2004). According to the model, the availability of personal (e.g., self-efficacy) and situational (e.g., social support) resources to meet demands within one's environment (e.g., work overload, challenging goals) help to decrease the likelihood of burnout and promote engagement. Although the introduction of engagement was influenced at least in part by positive psychology, much of the research conducted to investigate the implications of engagement for well-being has focused on stress reduction rather than health promotion (e.g., Demerouti et al., 2001; Peterson et al., 2008). Again, this may be due to the absence of more positive measures that are sensitive enough to detect the short-term psychological health benefits of engagement. In the present study, we included measures of engagement and burnout to determine whether they relate to the PGDS as would be expected according to the JD-R model.

\section{Research Objectives and Hypotheses}

Our core objective was to develop and validate a context-specific measure of personal growth and development. As part of the validation process, we administered other measures of well-being, including the SPWB, to our various samples. We expected moderate positive correlations between the PGDS and positive indicators of well-being (SPWB, life satisfaction, positive affect), and moderate negative 
correlations with negative indicators (negative affect, physical health complaints), suggesting that although related, the constructs being measured are distinct.

Hypothesis 1: The PGDS has a moderate positive correlation with the SPWB (global), life satisfaction, and positive affect, and a moderate negative correlation with negative affect and physical health complaints.

We also measured key variables from SDT (need satisfaction; motivational states) and the JD-R model (engagement; burnout) to serve as a nomological network in the validation of the PGDS. We expected that individuals who are engaged in their activities (work or studies), are autonomously motivated, and experience satisfaction of their needs for autonomy, competence, and relatedness, would report higher levels of personal growth and development resulting from these activities. Those who experience burnout and extrinsic regulation (material and social) should report lower levels of personal growth and development.

Hypothesis 2: The PGDS correlates positively with engagement, autonomous motivation (intrinsic motivation and identified regulation), and need satisfaction, and negatively with burnout, and external regulation.

Finally, to investigate whether the PGDS would be more sensitive than the SPWB to contextspecific conditions as expected, we examined the relative stability of the two measures over time, in a longitudinal student sample. We also examined the time-lagged relations between the two measures. We expected that, as a measure of general well-being, the SPWB (global) would be more stable over time than the context-specific PGDS. We also expected that initial levels of the global SPWB would be a better predictor of change in the PGDS than vice versa.

Hypothesis 3: SPWB (global) scores are more stable over time than are PGDS scores.

Hypothesis 4: SPWB (global) at Time 1 predicts changes in the PGDS at Time 2 better than the PGDS at Time 1 predicts the SPWB (global) at Time 2.

PRELIMINARY SCALE DEVELOPMENT

As noted previously, we used Ryff's (1989) general model as a guide to ensure breadth of content in a unidimensional measure of personal growth and development. We started by modifying definitions of the five relevant content domains to reflect the shift from a stable state to a state of change (see Table 1). Guided by these definitions, a team of seven individuals familiar with the research objectives worked independently to write items relevant to the five content domains. Following initial screening for clarity and redundancy, this process generated between 8 and 12 items for each domain. These items were then compiled in random order and presented to the same individuals who rated their relevance to each of the five domains. Items rated as being most relevant to the intended category by at least $75 \%$ of the judges were retained. These items were then further scrutinized for clarity, readability, and content breadth, and three items from each of the five domains were selected for inclusion on the 15-item PGDS to be administered in our main study (see Appendix).

\section{Method}

Data for our study were collected from two student samples and one employee sample. The first of the two student samples and the employee sample were cross-sectional; the second student sample was longitudinal. The 15-item PGDS was administered to each sample along with other measures described below. The item stem for the student samples was "My university experience so far has helped me...." and the stem for the employee sample was "My experience at my current workplace over the last year has helped me...." Responses were made on a 7-point scale with anchors ranging from 1 (Not at all) to 7 (Very much so). Descriptions of the samples, data collection procedures, and other measures are as follows.

\section{Sample 1 (Cross-sectional Student)}

Participants and procedure.

Students were recruited from an introductory psychology research participant pool and received research credits for participation. Data were collected using an online survey administered near the end of the academic year. Prior to analysis, data were screened for careless responding. Data from participants who responded incorrectly to two or more quality check items (directed item responses; see Kam \& 
Meyer, 2015) or completed the survey in less than 10 minutes (average response time was 30 minutes) were removed. Thus, the initial sample of 272 was reduced to 241. Participant age ranged from 17 to 28 years $(M=18.48, S D=.90)$, and $62 \%$ of the sample identified as female, with the remaining $38 \%$ identifying as male. Two-thirds of the sample indicated they were Caucasian (67\%), while 15\% indicated they were Chinese, and 9\% identified as South Asian.

\section{Measures.}

Global psychological well-being. Psychological well-being was assessed with the short 18-item version of the SPWB (Ryff, 1989). A sample item for this measure, taken from the Autonomy subscale, was "I feel like I am free to decide for myself how to live my life." Responses were made on 6-point scales with anchors ranging from 1 (Strongly disagree) to 6 (Strongly agree).

Basic need satisfaction. The Basic Needs Satisfaction in General scale (BNS-G; Gagné, 2003) as revised by Johnston and Finney (2010) was used to assess satisfaction of the three SDT needs. Autonomy was measured with 3 items (e.g., "I feel like I am free to decide for myself how to live my life."), competence with 6 items (e.g., "People I know tell me I am good at what I do."), and relatedness with 7 items (e.g., "I really like the people that I interact with."). Responses were made on 7-point scales with anchors ranging from 1 (Not at all true) to 7 (Very true).

Burnout. Emotional exhaustion (5 items; e.g., "I feel emotionally drained by my studies.") and cynicism about one's studies (4 items; e.g., "I have become less enthusiastic about my studies.") were measured using the student version of the Maslach Burnout Inventory (Schaufeli, Martinez, Marques Pinto, Salanova, \& Bakker, 2002). Responses were made on 7-point frequency scales with anchors ranging from 1 (Never) to 7 (Always).

Engagement. The student version of the Utrecht Work Engagement scale (Schaufeli, Salanova, González-Romá, \& Bakker, 2002) was used to measure three dimensions of engagement: vigor (6 items; e.g., "When I get up in the morning, I feel like going to class."), dedication; (5 items; e.g., "My studies inspire me."), and absorption (6 items; e.g., "Time flies when I am studying."). Responses were made on 7-point frequency scales with anchors ranging from 1 (Never) to 7 (Always).

Positive and negative affectivity. Positive (e.g., "Interested") and negative affectivity (e.g., "Distressed") were measured with the Positive and Negative Affect Schedule (PANAS; Watson, Clark, \& Tellegen, 1988). Participants indicated their agreement with 20 statements regarding their feelings during the academic year. Responses were made on 5-point scales with anchors ranging from 1 (Very slightly or not at all) to 5 (Extremely).

Physical health complaints. The 14-item Physical Health Questionnaire (PHQ; Schat, Kelloway, \& Desmarais, 2005) was used to measure four dimensions of physical health: gastrointestinal problems (4 items; e.g., "How often have you suffered from an upset stomach (indigestion)?"), headaches (3 items; e.g., "How often have you experienced headaches?"), sleep disturbances (4 items; e.g., "How often have you woken up during the night?"), and respiratory illnesses (3 items; e.g., "How many times have you had minor colds [that made you feel uncomfortable but didn't keep you sick in bed or make you miss work]?"). Responses were made on 7-point scales with anchors ranging from 1 (Not at all) to 7 (All of the time).

\section{Sample 2 (Cross-sectional Employee)}

Participants and procedure.

A sample of working adults was recruited through Amazon's Mechanical Turk (Mturk) to complete an online survey concerning work attitudes and well-being. To participate, individuals were required to be working full- or part-time (beyond the work performed through Mturk) and to be fluent in English. We received 543 completed surveys, but the final sample was reduced to 468 (247 males, 218 females, 3 other) following removal of individuals who failed validity checks like those in Sample 1 or did not meet inclusion criteria. Participants ranged in age from 18 to 84 years $(M=36.90, S D=10.98)$; 10 individuals did not indicate their age. A majority of participants were Caucasian (82.5\%), with most others identifying as Black (7.1\%), Latin American (4.7\%), and Chinese (3.4\%). Most $(n=432)$ were employed full-time and the remainder $(n=36)$ worked part-time.

\section{Measures.}


Basic need satisfaction. We measured need satisfaction using the Basic Need Satisfaction at Work Scale (BNS-W; Deci et al., 2001; Ilardi, Leone, Kasser, \& Ryan, 1993). The items are similar to the BNS-G used in Sample 1, but with a focus on work rather than life in general (e.g., people at work care about me vs. people in my life care about me).

Work motivation. We measured the SDT motivational states using a slightly modified version of the Multidimensional Work Motivation scales (MWMS) developed by Gagné et al. (2015). Modifications included slight wording changes to the instructions and items to improve clarity. Items on the MWMS identify reasons for putting effort into one's job and reflect six distinct motivational states, four of which were relevant to the present investigation: extrinsic regulation-social (3 items; e.g., "To get others' approval (e.g., supervisor, colleagues, family, clients...).”), extrinsic regulation-material (3 items; e.g., "Because I risk losing my job if I don't put enough effort into it."), identified regulation (3 items; e.g., "Because putting effort into this job aligns with my personal values."), and intrinsic motivation ( 3 items; e.g., "Because the work I do is interesting."). Amotivation and introjection were measured but not included in our hypotheses or analyses. Responses were made on 7-point scales with anchors ranging from 1 (Strongly Disagree) to 7 (Strongly Agree).

Satisfaction with life. Respondents completed the 5-item Satisfaction with Life Scale (SWLS; Diener, Emmons, Larsen, \& Griffin, 1985). A sample item is "I am satisfied with my life." Responses were made on a 7-point scale with anchors ranging from 1 (Strongly disagree) to 7 (Strongly agree).

Physical health complaints. As in Sample 1, we used the PHQ (Schat et al., 2005) to measure physical health complaints within the last year.

\section{Sample 3 (Longitudinal Student)}

\section{Participants and procedure.}

As in Sample 1, students were recruited from an introductory psychology research participant pool and received research credits for participation. Students completed online surveys at approximately the midpoint of the first semester $(n=720)$ and again approximately 4 months later, near the end of the second semester $(n=439)$. Following similar screening procedures as in the earlier studies, data were retained for 656 participants at Time 1 and 403 at Time 2. Logistic regressions were used to test the assumption that the missing data were missing completely at random (MCAR). The results indicated that participant drop-out status after Time 1 was not related to any of the Time 1 variables. Data for 377 participants were matched using a student-generated identification code, and analyses were conducted on this reduced sample. The age range of matched participants was 17 to 36 years $(M=18.16, S D=1.22)$, with $80 \%$ identifying as female, $19 \%$ as male, and less than $1 \%$ as neither. Approximately $50 \%$ of the sample indicated they were Caucasian, while $19.4 \%$ indicated they were Chinese, and $11.7 \%$ identified as South Asian.

\section{Measures.}

Global psychological well-being. Global psychological well-being was measured using the 54item version of the SPWB, with nine items per dimension (Ryff, 1989).

Basic need satisfaction. As in Sample 1, the BNS-G (Gagné, 2003) was used to assess satisfaction of the need for autonomy (7 items), competence (6 items), and relatedness ( 8 items).

Motivation. We measured the SDT motivational states using a 22-item measure adapted from the MWMS used in Sample 2 (Gagné et al., 2015). As in Sample 2, the items for amotivation and introjection were administered but not included in our analyses. Rather than asking about reasons for putting effort into a job, participants were asked to indicate the reasons they put effort into their studies (e.g., "To avoid getting bad grades"; "Because putting effort into my studies aligns with my personal values"). Responses were made on 7-point scales with anchors ranging from 1 (Not at all) to 7 (Completely).

\section{PGDS Dimensionality}

\section{Results}

Although the PGDS items were written to reflect five content domains from Ryff's (1989) model, our objective was to develop a relatively short unidimensional measure of personal growth and development. To determine whether the item variance could be adequately captured with a single dimension, we conducted CFA with data from each of the three samples. 
For comparison, we also tested the fit of a five-factor model with three items representing each of the content domains. These and all subsequent analyses were conducted with Mplus software version 6.12 (Muthén \& Muthén, 1998-2011) using robust maximum likelihood estimation (MLR). Fit was evaluated using the Comparative Fit Index (CFI), the Tucker Lewis Index (TLI), the Root Mean Square Error of Approximation (RMSEA), and the Standardized Root Mean Residual (SRMR). As suggested by Hu and Bentler (1999), CFI and TLI values greater than .90 demonstrate acceptable fit, while values greater than .95 indicate excellent fit, and SRMR values below .08 support relatively good fit. RMSEA values below .08 indicate acceptable fit, while values below .05 support good fit (Browne \& Cudeck, 1993).

In all cases, the CFI and TLI values exceeded .90 (Sample $1=.922 ;$ Sample $2=.914$; Sample 3 $T 1=.932 ;$ Sample $3 T 2=.940)$, and the SRMR values fell below .05 (Sample $1=.048 ;$ Sample $2=.043$; Sample $3 T 1=.043$; Sample $3 T 2=.042)$, indicating acceptable fit. With one exception, the RMSEA values fell below .08 (Sample $1=.076$ [.063, .089]; Sample $2=.086$ [.077, .094]; Sample $3 T 1=.060$ $[.050, .071]$; Sample $3 T 2=.058[.047, .068]$ ), again suggesting acceptable fit. Item loadings and omega coefficients for each sample/time on the unidimensional scale can be seen in Table 2. In contrast, for all samples, the latent variable covariance matrix for the 5-factor solution was non-positive definite, indicating that the parameters are untrustworthy. Closer inspection suggested that this was likely due to the very high correlations among the latent variables (exceeding 1.0 in some cases). In light of these findings, we felt justified in treating the PGDS as a unidimensional measure. The coefficient alphas for the 15 -item measure were above .90 for all samples.

\section{Measurement Invariance}

To test for measurement invariance across samples, contexts, and time, we conducted multi-group CFA following the procedures outlined by Vandenberg and Lance (2000). The cross-sample analyses were conducted with the cross-sectional student sample and the T2 data from the longitudinal sample. We chose the T2 data because it was collected at approximately the same time within the academic year as the cross-sectional sample data. The cross-time analyses were conducted with the T1 and T2 data from the longitudinal student sample. Finally, the cross-context analyses were conducted with the cross-sectional student sample and the work sample. Although demonstrating measurement invariance across the education and work contexts is arguably less important than demonstrating invariance across samples and time within a specific context, it provides some evidence concerning the generalizability of the construct. We tested for configural invariance by examining the fit for a 1-factor model for the various sample pairings. We then tested for metric invariance by fixing the factor loadings to be equal across samples. Next, we tested for scalar invariance by fixing the item intercepts to be equal across samples. In each of these sequential analyses, we compared the fit of the more constrained model to that for the less constrained model. Because the commonly used chi-square difference tests are known to be highly sensitive to sample size (Marsh, Hau, \& Grayson, 2005), we followed Chen's (2007) recommendation to consider changes in the CFI and RMSEA values. Chen suggested that differences can be considered significant (suggesting non-invariance) if the decrease in CFI for the constrained model is greater than .010 , and the increase in RMSEA is greater than .015, compared to the unconstrained model.

The results of the invariance analyses are reported in Table 3. As can be seen, using Chen's (2007) criteria, we found evidence for metric invariance in all comparisons. We found evidence for scalar invariance for the longitudinal sample, but evidence for the cross-student sample was mixed (i.e., supported by change in RMSEA but not by change in CFI). Evidence for metric equivalence is sufficient to justify comparison of variable relationships across sample/occasions, whereas scalar equivalence is required for comparison of means across groups. Thus, the mixed evidence for scalar invariance in the student samples suggests that caution is warranted in making group comparisons. Although we did not find evidence for scalar invariance across the student and employee samples, this is of no concern because comparisons of mean scores across contexts are not inherently meaningful.

\section{Construct Validity of the PGDS}

We hypothesized that the PGDS would have a moderate positive correlation with other positive indicators of well-being and a moderate negative correlation with negative indicators. A moderate correlation provides evidence for both convergent and discriminant validity. That is, it suggests that the 
PGDS relates positively with other measures of well-being as it should (convergent validity), but that the correlations are not sufficiently large to suggest redundancy (discriminant validity). The within-time correlations among the well-being measures across the three samples are reported in Tables 4-6, and the time-lagged relations for the longitudinal sample are reported in Table 7.

The correlations between the PGDS and the SPWB reported across the three samples are of particular interest given that they are both based on Ryff's (1989) theoretical model, with one intended to measure a relatively stable global construct and the other a more context-specific and dynamic construct. As can be seen in Tables 4 and 6, consistent with Hypothesis 1, the correlations between the PGDS and the SPWB (global) range from .53 to .70 in the student samples. Correlations with other indicators of psychological well-being (i.e., life satisfaction; positive and negative affect) are also in the expected direction and of moderate strength (see Tables 4-6). Interestingly, correlations with physical health complaints measured with the PHQ were negative, but somewhat weaker than expected (-.14 in Sample 1 and -.16 in Sample 2). Overall, Hypothesis 1 is generally supported.

We also measured several variables from SDT and the JD-R model to serve as a nomological network for validation purposes. The within-time correlations are reported in Tables 4-6, and the timelagged relations for students are reported in Table 7. As can be seen, the PGDS correlates positively with measures of need satisfaction, intrinsic motivation, identified regulation, and engagement, and negatively with burnout both within and across time. These findings support Hypothesis 2 and provide further evidence for the construct validity of the PGDS. Contrary to expectation, however, correlations between the PGDS and the two extrinsic regulation scales (social and material) in Samples 2 and 3 were positive, albeit weak. One possible explanation for these unexpected findings is provided in the Discussion section. Construct Stability and Relation to Global Well-being

To test Hypothesis 3, that general psychological well-being as measured by the SPWB is a more stable construct than context-specific personal growth and development as reflected in the PGDS, we used structural equation modeling (SEM) to test the model depicted in Figure 1. This analysis also addresses Hypothesis 4, that general well-being at Time 1 is a better predictor of change in personal growth and development than vice versa. We conducted these analyses with factor scores because they provide some control of measurement error (Morin, Arens, \& Marsh, 2016). The factor scores for the PGDS were derived from the 1-factor CFA reported earlier. A comparable 1-factor model for the SPWB did not fit the data well at Time 1 (RMSEA $=.074[.071, .076]$; CFI $=.610 ; \mathrm{TLI}=.595)$ or Time 2 $(\mathrm{RMSEA}=.075[.072, .077]$; CFI $=.643$; TLI $=.629)$. Therefore, following Espinoza et al. (2018), we conducted a bifactor ESEM with one global factor and six specific factors. We conducted ESEM rather than a CFA because it allows for cross-loadings on the specific factors and is more realistic in situations like the present where the constructs being measured are highly correlated (Gignac, 2016).

The fit for the bifactor ESEM of the SPWB was modest, reaching acceptable levels for the RMSEA at both time points, for CFI at Time 2, but not for TLI at either time (RMSEA $=.050[.047$, $.053], \mathrm{CFI}=.860$, and TLI $=.813$ at Time 1 ; RMSEA $=.042[.039, .045]$, CFI $=.911$, and TLI $=.882$ at Time 2). We also examined the parameter estimates, in line with the recommendations of Morin and colleagues (e.g., Morin et al., 2016; Tóth-Király, Morin, Bőthe, Orosz, \& Rigó, 2018), and found that the items loaded well on the global factor. Further, the global factor accounted for a substantial portion of the variance in items across the six content domains, as exhibited by omega hierarchical coefficient values $(\mathrm{T} 1=.65 ; \mathrm{T} 2=.69)$ well above the minimum guideline of .50 (Reise, Bonifay, \& Haviland, 2013). The omega hierarchical coefficient (McDonald, 1999; Zinbarg, Barlow, \& Brown, 1997; Zinbarg, Revelle, Yovel, \& Li, 2005) is an alternative to coefficient alpha that is useful in bifactor structures because it estimates the proportion of variance in observed scores attributable to the global factor. Therefore, for present purposes, we treated the bifactor as an indicator of global psychological well-being and used scores on this factor in our cross-lagged analyses.

The results of the SEM are reported in Figure 1. As expected, the stability coefficient for the $\operatorname{SPWB}(\beta=.840[\mathrm{CI}=.756, .924])$ is stronger than that for the PGDS $(\beta=.572[\mathrm{CI}=.460, .683])$. The 95 percent confidence intervals around these path estimates do not overlap suggesting that the difference is significant. Moreover, the path linking the T1 SPWB (global) to the T2 PGDS ( $\beta=.235[\mathrm{CI}=.118$, 
$.352]$ ) is significant and positive, whereas the path from the T1 PGDS to the T2 SPWB (global) is negative but not significant $(\beta=-.026[\mathrm{CI}=-.117, .065])$. Again, the 95 percent confidence intervals do not overlap, suggesting that the difference is significant. Therefore, Hypotheses 3 and 4 are supported.

\section{Creating Shorter Versions of the PGDS}

Our objective was to develop a short unidimensional measure of personal growth and development for use in research and in practice. Although a 15-item measure is relatively short when considering that it includes five content domains, some might argue that a 15 -item measure is too long and that both researchers and practitioners are under increasing pressure to keep survey length to a minimum. Therefore, we conducted additional analyses to determine whether our basic findings would replicate using a 10- or 5-item version of the measure. In the Appendix, we identify items that might be selected for this purpose. These shortened scales were created based on item loadings on the 1-factor CFA of the 15-item PGDS across the three samples. The correlations between the 10- and 15-item PGDS ranged from $r=.98-.99$, and the correlations between the 5- and 15-item PGDS ranged from $r=.93-.96$ across the three samples. The Cronbach alphas for the 10- and 5- item PGDS ranged from $\alpha=.88-.94$ and $\alpha=.80-.90$, respectively, across the three samples. Finally, correlations between the short PGDS measures and the other measures included in our samples were virtually identical (see Tables S1 to S3, in the supplementary materials).

\section{DISCUSSION}

Despite the increasing interest in a more positive conceptualization of psychological well-being, relatively little attention has been paid to measurement of the construct other than at a general level. Measures of positive well-being as a psychologically healthy lifestyle (e.g., Ryff, 1989; Waterman et al., 2010) are not well-suited to testing theory purporting the benefits of context-specific experiences for psychological well-being. A case in point is research pertaining to the JD-R model where measures of psychological ill-health have been used in the investigation of burnout, but investigation of the positive psychological health benefits of engagement is lacking. Similarly, according to SDT, need satisfaction and autonomous motivation are expected to contribute to positive psychological health, but researchers have generally relied on negative indicators of well-being (e.g., anxiety and stress) to test the theory. To address this issue, we developed an instrument to measure perceptions of personal growth and development and evaluated the measure within an academic and work context. As part of the validation process, we demonstrated that the PGDS is related to, but distinguishable from, other measures of wellbeing including Ryff's (1989) SPWB. Importantly, we demonstrated that the SPWB (global) measures a more stable construct and that it predicts change in PGDS scores over time. Finally, by demonstrating that the PGDS relates as expected to key variables from SDT and the JD-R model, we provided further evidence for its construct validity and its utility as an outcome measure in tests of these theories.

\section{Global and Context-specific Psychological Well-being}

Our argument for the need for a context-specific measure of psychological well-being was premised on the notion that existing measures of positive well-being reflect a relatively stable lifestyle that is not amenable to investigation of the effects of specific experiences, such as those proposed in SDT and the JD-R model. We provided particularly strong support for this argument in our longitudinal investigation of the relation between the SPWB (global) and the PGDS. Not only was the stability coefficient greater for the SPWB than for the PGDS, but the SPWB significantly predicted change in PGDS scores over a four-month period, whereas the PGDS did not predict change in the SPWB scores. That is, students who reported greater overall psychological health early in the academic year reported greater growth and development near the end of the year than did those with lower overall well-being.

Admittedly, we examined the relation between global and context-specific positive psychological well-being over a relatively short period of time (i.e., approximately four months). It is possible that, over the longer term, repeated exposure to opportunities for personal growth and development will contribute to improvements in overall psychological well-being. Indeed, this would be completely consistent with Ryff's (1989) model of psychological well-being and the large body of supporting evidence (see Ryff, 2014). However, the fact that we observed less stability in the PGDS than the SPWB over time, and that 
the PGDS related as expected to key variables within SDT and the JD-R model suggests that it is particularly well-suited to research pertaining to improvements in positive well-being.

\section{Applications of the PGDS}

In the present research, we demonstrated the relevance of our measure to SDT and JD-R model

research. As expected, the PGDS correlated positively with need satisfaction and autonomous motivation in both students and employees, and with student engagement. The PGDS also correlated negatively with burnout in students, as predicted. These findings are consistent with theory and previous research but are among the first to involve a measure of positive psychological well-being. Thus, the PGDS could serve as a useful tool in future research pertaining to both SDT and the JD-R model.

As an aside, our analyses for Samples 2 and 3 yielded some unexpected results. Specifically, the correlations between the PGDS and the two extrinsic regulation scales (social and material) were positive, albeit weak, rather than negative as predicted. Our initial predictions were based on the theoretical argument that controlled forms of regulation can undermine psychological health (Ryan \& Deci, 2000). Although there is some support for this prediction in variable-centered research (e.g., Deci, Koestner, \& Ryan, 1999; Ryan \& Deci, 2000), relations between measures of external regulation and well-being tend to be modest, and considerably weaker than the correlations involving autonomous regulation. This can be explained by recent person-centered (profile) research demonstrating that individuals can experience both autonomous and controlled forms of motivation simultaneously (e.g., Howard, Gagné, Morin, \& Van den Broeck, 2016; Moran, Diefendorff, Kim, \& Liu, 2012), in which case the negative effects of controlled motivation may be mitigated. This might also explain why external regulation was found to have weak positive (rather than negative) correlations with identified regulation and intrinsic motivation in Howard, Gagné, and Bureau's (2017) recent meta-analysis. The zero-order correlations reported in Tables 5-6, and in variable-centered studies in general, do not distinguish pure external control from the combined conditions, but the fact that the correlations are weak is consistent with this notion. Therefore, although contrary to our initial hypothesis based on theory, the unexpected findings for external regulation are consistent with more recent findings from person-centered research and do not undermine our general conclusions regarding the validity of the PGDS.

There are many theories besides SDT and the JD-R model where positive psychological benefits are directly stated or implied. For example, Meyer and Maltin (2010) proposed a theoretical framework linking employee commitment to well-being. Their review of the literature demonstrated expected relations with several indicators of physical and psychological well-being, but they lamented the fact that most studies included negative health indicators (e.g., stress, burnout) and that there was a dearth of research including more positive measures. Among the many other constructs that have been linked in theory to psychological well-being are empowerment (e.g., Biron \& Bamberger, 2010), authentic leadership (Gardner, Cogliser, Davis, \& Dickens, 2011), and job design (Humphrey, Nahrgang, \& Morgeson, 2007). The PGDS has considerable potential for the investigation of these links, as well as to the evaluation of interventions in the practical applications of these theories.

In sum, the PGDS was developed as a context-specific measure of positive psychological wellbeing. By context we are referring to a general setting (e.g., school or work) in which an individual might have many occasion-specific experiences (e.g., getting feedback on a term paper; being consulted by a manager on a decision). The PGDS was designed to be more sensitive than global measures such as the SPWB to the relatively short-term implications of context-specific experiences. Therefore, it is likely to be most useful to researchers and practitioners interested in understanding the implications of specific conditions (e.g., autonomy support, job demands/resources) and/or interventions for changes in psychological well-being. As a caveat, we note that, without further research, it is difficult to know to what extent the PGDS will be sensitive to occasion-specific experiences that occur within a broader context. Therefore, its applications in experience-sampling or daily diary studies might warrant further investigation.

\section{Limitations and Future Directions}

Although based on a multidimensional model of psychological well-being, the PGDS was designed as a unidimensional measure with content reflecting different substantive domains. The CFAs 
conducted across samples revealed that the fit of a one-factor model was acceptable but not perfect. The alpha (raw score reliability) and omega (latent variable reliability) values also reached acceptable levels thereby justifying use of the PGDS as a unidimensional measure of context-specific personal growth and development in future research and practice. The lack of perfect fit in the CFA is likely attributable to the diversity of item content within a short measure. We found no evidence to support a five-factor structure for the current PGDS but, with the addition of more items, development of a reliable multidimensional measure might be possible for those who are interested in assessing more domain-specific personal growth and development.

We used Ryff's (1989) SPWB to measure global psychological well-being in our student samples. Again, for present purposes, we were interested in treating the SPWB as a unidimensional measure. However, a one-factor model tested in CFA provided a poor fit to the data. Therefore, following Espinoza et al. (2018), we conducted a bifactor ESEM and found that the general factor accounted for a substantial portion of the variance across items. The omega value for the general factor was also acceptable, therefore justifying its use as a measure of global well-being for our purposes. However, closer examination revealed that several items had relatively low loadings on both the global and targeted specific factor (see Tables S4 and S5 in the supplementary materials). These findings, in conjunction with those reported by Espinoza et al. (2018), suggest the need for refinement of the SPWB. Considering these problems, future tests of our hypotheses regarding the within- and time-lagged relationships between global and context-specific well-being using alternative measures of global well-being might be warranted.

In this investigation, we found mixed support for measurement invariance for the PGDS across our samples. The evidence we provided for metric invariance across student samples and over time suggests that our measure is suited to the investigation of relationships with other variables within and across time (at least for students). However, comparison of means across groups requires evidence for scalar invariance (Chen, 2007) and, although we found evidence for scalar invariance in the longitudinal student sample, the evidence we obtained across student samples was not definitive. Therefore, we encourage additional research with students and other samples to investigate scalar equivalence to justify use of the PGDS for cross-group comparisons or the evaluation of interventions.

In the present research, we only evaluated the PGDS within academic and work contexts. However, as noted earlier, it has the potential for application in a variety of other contexts where demands are a source of stress and resources can mitigate these effects and contribute to engagement (e.g., sport and exercise; volunteering). Further, the design of the scale, with a fixed set of items and a stem that can be adjusted to suit the context, facilitates its use beyond the two contexts investigated in this study. Therefore, the PGDS might serve as a useful research tool in a variety of contexts, and the results of this research will have implications for the generalizability of our findings.

Our data were also obtained using self-report data. All of the primary constructs we measured in this research reflect internal states and are arguably best measured with self-reports. It is certainly possible to complement these self-report measures with others' perceptions of the targets' psychological well-being, engagement, or burnout, and this is a viable direction for future research. It would also be helpful to examine the relations between the PGDS and more objective measures of health, behavior, or performance.

One of the concerns regarding the use of same-source measures is inflation of correlations. We were able to address these concerns in several ways. First, we conducted CFAs to demonstrate that the constructs being measured were distinct from the PGDS. Second, we examined relations over time in a sample of students. This serves the purpose of mitigating consistency biases that can occur in within-time analyses. More importantly, we demonstrated that the Time 1 measure of global psychological well-being relates as it should with the PGDS at Time 2 even with the Time 1 measure controlled. If common method bias were an issue, it would have worked against us in testing our hypotheses regarding timelagged relations.

Finally, one of our objectives in developing the PGDS was for use in investigating the positive health benefits of context-specific conditions and/or interventions, such as those proposed in SDT (e.g., 
autonomy support) and the JD-R model (e.g., demands and resources). However, the covariates we included in our study (e.g., need satisfaction, engagement, burnout) are arguably proxies for more specific conditions. Indeed, from a theoretical perspective, they would be considered mediators between the specific conditions and well-being. Therefore, we encourage future investigation of the relations with, or impact of, specific conditions or interventions on PGDS scores.

\section{Conclusions}

We demonstrated that it is possible to measure improvement in positive psychological well-being within specific contexts, and to distinguish it from a measure of global psychological well-being. In addition to developing the PGDS as such a measure, we demonstrated its utility in tests of the hypothesized relations with key constructs from SDT (need satisfaction and motivational state) and the JD-R model (burnout and engagement). We also examined the relationship between global psychological well-being and perceived personal growth and development over time and found evidence that those who are generally healthier show greater improvement in well-being through their experiences. Although we demonstrated the utility of the PGDS in an educational and work context, it has the potential for application in a wider variety of contexts. 


\section{References}

Allport, G. W. (1961). Pattern and growth in personality. New York, NY: Holt, Rinehart, and Winston. Aristotle (1985). Nicomachean ethics (T. Irwin, Trans.). Indianapolis, IN: Hackett.

Benedetti, A. A., Diefendorff, J. M., Gabriel, A. S., \& Chandler, M. M (2015). The effects of intrinsic and extrinsic sources of motivation on well-being depend on time of day: The moderating effect of workday accumulation. Journal of Vocational Behavior, 88, 38-46.

Biron, M., \& Bamberger, P. (2010). The impact of structural empowerment on individual well-being and performance: Taking agent preferences, self-efficacy and operational constraints into account. Human Relations, 62(2), 163-191.

Browne, M. W., \& Cudeck, R. (1993). Alternative ways of assessing model fit. In K. A. Bollen \& J. S. Long (Eds.), Testing Structural Equation models (pp. 136-162). Newbury Park, CA: Sage.

Chen, F. F. (2007). Sensitivity of goodness of fit indexes to lack of measurement invariance. Structural Equation Modeling: A Multidisciplinary Journal, 14(3), 464-504.

Cronbach, L. J., \& Meehl, P. E. (1955). Construct validation in psychological tests. Psychological Bulletin, 52(4), 281-302.

Deci, E. L., Koestner, R., \& Ryan, R. M. (1999). A meta-analytic review of experiments examining the effects of extrinsic rewards on intrinsic motivation. Psychological Bulletin, 125, 627-668.

Deci, E. L., \& Ryan, R. M. (1985). Intrinsic motivation and self-determination in human behavior. New York, NY: Plenum.

Deci, E. L., \& Ryan, R. M. (2000). The "what" and "why" of goal pursuits: Human needs and the selfdetermination of behavior. Psychological Inquiry, 11, 227-268.

Deci, E. L., \& Ryan, R. M. (2014). The importance of universal psychological needs for understanding motivation in the workplace. In M. Gagné (Ed.), The Oxford Handbook of Work Engagement, Motivation, and Self-Determination Theory (pp. 13-32). New York, NY: Oxford University Press.

Deci, E. L., Ryan, R. M., Gagné, M., Leone, D. R., Usunov, J., \& Kornazheva, B. P. (2001). Need satisfaction, motivation, and well-being in the work organizations of a former Eastern Bloc country: A cross-cultural study of self-determination. Personality and Social Psychology Bulletin, 27, 930-942.

Demerouti, E., Bakker, A. B., Nachreiner, F., \& Schaufeli, W. B. (2001). The job demands-resources model of burnout. Journal of Applied Psychology, 86(3), 499-512.

Deng, N., Guyer, R., \& Ware, J. E. (2015). Energy, fatigue, or both? A bifactor modeling approach to the conceptualization and measurement of vitality. Quality of life Research, 24, 81-93.

Diener, E., Emmons, R. A., Larsen, R. J., \& Griffin, S. (1985). The satisfaction with life scale. Journal of Personality Assessment, 49(1), 71-75.

Diener, E., Wirtz, D., Tov, W., Kim-Prieto, C., Choi, D., Oishi, S., \& Biswas-Diener, R. (2010). New well-being measures: Short scales to assess flourishing and positive and negative feelings. Social Indicators Research, 97, 143-156.

Espinoza, J. A., Meyer, J. P., Anderson, B. K., Vaters, C., \& Politis, C. (2018). Evidence for a bifactor structure of the scales of psychological well-being using exploratory structural equation modeling. Journal of Well-being Assessment, 2(1), 21-40.

Gagné, M. (2003). The role of autonomy support and autonomy orientation in prosocial behaviour engagement. Motivation and Emotion, 27, 199-223.

Gagné, M., \& Deci, E. L. (2005). Self-determination theory and work motivation. Journal of Organizational Behaviour, 26, 331-362.

Gagné, M., Forest, J., Vansteenkiste, M., Crevier-Braud, L., Van den Broeck, A., Aspeli, A. K., Bellerose, J., ... Westbye, C. (2015). The multidimensional work motivation scale: Validation evidence in seven languages and nine countries. European Journal of Work and Organizational Psychology, 24(2), 178-196.

Gardner, W. L., Cogliser, C. C., Davis, K. M., \& Dickens, M. P. (2011). Authentic leadership: A review of the literature and research agenda. The Leadership Quarterly, 22(6), 1120-1145. 
Gignac, G. E. (2016). The higher-order model imposes a proportionality constraint: That is why the bifactor model tends to fit better. Intelligence, 55, 57-68.

Hinkin, T. R. (1998). A brief tutorial on the development of measures for use in survey questionnaires. Organizational Research Methods, 1, 104-121.

Howard, J. L., Gagné, M., \& Bureau, J. S. (2017). Testing a continuum structure of self-determined motivation: A meta-analysis. Psychological Bulletin, 143(12), 1346-1377.

Howard, J., Gagné, M., Morin, A. J. S., \& Van den Broeck, A. (2016). Motivation profiles at work: A self-determination theory approach. Journal of Vocational Behaviour, 95-96, 74-89.

Hu, L. T., \& Bentler, P. M. (1999). Cutoff criteria for fit indexes in covariance structure analysis: Conventional criteria versus new alternatives. Structural Equation Modeling: A Multidisciplinary Journal, 6(1), 1-55.

Humphrey, S. E., Nahrgang, J. D., \& Morgeson, F. P. (2007). Integrating motivational, social and contextual work design features: A meta-analytic summary and theoretical extension of the work design literature. Journal of Applied Psychology, 92(5), 1332-1356.

Ilardi, B. C., Leone, D., Kasser, R., \& Ryan, R. M. (1993). Employee and supervisor ratings of motivation: Main effects and discrepancies associated with job satisfaction and adjustment in a factory setting. Journal of Applied Social Psychology, 23, 1789-1805.

Johnston, M. M., \& Finney, S. J. (2010). Measuring basic needs satisfaction: Evaluating previous research and conducting new psychometric evaluations of the basic needs satisfaction in general scale. Contemporary Educational Psychology, 35, 280-296.

Kafka, G. J., \& Kozma, A. (2002). The construct validity of Ryff's scales of psychological wellbeing (SPWB) and their relationship to measures of subjective well-being. Social Indicators Research, 57(2), 171-190.

Kam, C. C. S., \& Meyer, J. P. (2015). How careless responding and acquiescence response bias can influence construct dimensionality: The case of job satisfaction. Organizational Research Methods, 18(3), 512-541.

Karasek, R. A. (1979). Job demands, job decision latitude, and mental strain: Implications for job redesign. Administrative Science Quarterly, 24(2), 285-308.

Marsh, H. W., Hau, K.-T., \& Grayson, D. (2005). Goodness of fit evaluation in structural equation modeling. In A. Maydeu-Olivares, \& J. McArdle (Eds.), Contemporary psychometrics: A festschrift for roderick P. McDonald. Mahwah, NJ: Erlbaum.

Maslow, A. H. (1968). Toward a psychology of being. New York, NY: D. Van Nostrand Company.

McDonald, R. P. (1999). Test Theory: A Unified Treatment. Mahwah, NJ: Erlbaum.

Meyer, J. P., \& Maltin, E. R. (2010). Employee commitment and well-being: A critical review, theoretical framework, and research agenda. Journal of Vocational Behavior, 77, 323-337.

Moran, C. M., Diefendorff, J. M., Kim, T.-Y., \& Liu, Z.-Q. (2012). A profile approach to selfdetermination theory motivations at work. Journal of Vocational Behavior, 81(3), 354-363.

Morin, A. J. S., Arens, A., \& Marsh, H. (2016). A bifactor exploratory structural equation modeling framework for the identification of distinct sources of construct-relevant psychometric multidimensionality. Structural Equation Modeling, 23, 116-139.

Muthén, L. K., \& Muthén, B. O. (1998-2011). Mplus User's Guide. Sixth Edition. Los Angeles, CA: Muthén \& Muthén.

Parker, S. L., Jimmieson, N. L., \& Amiot, C. E. (2010). Self-determination as a moderator of demands and control: Implications for employee strain and engagement. Journal of Vocational Behavior, $76,53-67$.

Peterson, U., Demerouti, E., Bergström, G., Samuelsson, M., Åsberg, M., \& Nygren, Å. (2008). Burnout and physical and mental health among Swedish healthcare workers. Journal of Advanced Nursing, 62(1), 84-95. 
Porath, C., Spreitzer, G., Gibson, C., \& Garnett, F. G. (2012). Thriving at work: Toward its measurement, construct validation, and theoretical refinement. Journal of Organizational Behaviour, 33, 250275.

Reeve, J. (2002). Self-determination theory applied to educational settings. In E. L. Deci and R. M. Ryan (Eds.), Handbook of self-determination research (pp. 183-203). Rochester, NY: University of Rochester Press.

Ruini, C., Belaise, C., Brombin, C., Caffo, E, \& Fava, G. A. (2006). Well-being therapy in school settings: A pilot study. Psychotherapy and Psychosomatics, 75(6), 331-336.

Ryan, R. M., Curren, R. R., \& Deci, E. L. (2013). What humans need: Flourishing in Aristotelian philosophy and self-determination theory. In A. S. Waterman (Ed.), The best within us: Positive psychology perspectives on eudaimonia (pp. 57-75). Washington, DC: American Psychological Association.

Ryan, R. M., \& Deci, E. L. (2000). Self-determination theory and the facilitation of intrinsic motivation, social development, and well-being. American Psychologist, 55, 68-78.

Ryan, R. M., \& Deci, E. L. (2001). On happiness and human potentials: A review of research on hedonic and eudaimonic well-being. Annual Review of Psychology, 52(1), 141-166.

Ryan, R. M., Huta, V., \& Deci, E. L. (2008). Living well: a self-determination theory perspective on eudaimonia. Journal of Happiness Studies, 9, 139-170.

Ryff, C. D. (1989). Happiness is everything, or is it? Explorations on the meaning of psychological wellbeing. Journal of Personality and Social Psychology, 57(6), 1069-1081.

Ryff, C. D. (2014). Psychological well-being revisited: Advances in the science and practice of eudaimonia. Psychotherapy and Psychosomatics, 83(1), 10-28.

Ryff, C. D., \& Keyes, C. L. M. (1995). The structure of psychological well-being revisited. Journal of Personality and Social Psychology, 69(4), 719-727.

Ryff, C. D., \& Singer, B. H. (2006). Best news yet on the six-factor model of well-being. Social Science Research, 35(4), 1103-1119.

Schat, A. C. H., Kelloway, E. K., \& Desmarais, S. (2005). The physical health questionnaire (PHQ): Construct validation of a self-report scale of somatic symptoms. Journal of Occupational Health Psychology, 10(4), 363-381.

Schaufeli, W. B., \& Bakker, A. B. (2004). Job demands, job resources, and their relationship with burnout and engagement: A multi-sample study. Journal of Organizational Behaviour, 25(3), 293-315.

Schaufeli, W. B., Martinez, I. M., Marques Pinto, A., Salanova, M., \& Bakker, A. B. (2002). Burnout and engagement in university students: A cross-national study. Journal of Cross-Cultural Psychology, 33(5), 464-481.

Schaufeli, W. B., Salanova, M., González-Romá, V., \& Bakker, A. B. (2002). The measurement of engagement and burnout: A two sample confirmatory factor analytic approach. Journal of Happiness Studies, 3, 71-92.

Schaufeli, W. B., \& Taris, T. W. (2014). A critical review of the job demands-resources model: Implications for improving work and health. In G. F. Bauer \& O. Hämmig (Eds.), Bridging occupational, organizational and public health: A transdisciplinary approach (pp. 43-68). New York, NY: Springer Science + Business Media.

Schleicher, H., Alonso, C., Shirtcliff, E. A., Muller, D., Loevinger, B. L., \& Coe, C. L. (2005). In the face of pain: The relationship between psychological well-being and disability in women with fibromyalgia. Psychotherapy and Psychosomatics, 74(4), 231-239.

Schmitt, N. \& Ali, A. A. (2015). The practical importance of measurement invariance. In C. E. Lance \& R. J. Vandenberg. (Eds.), More Statistical and Methodological Myths and Urban Legends. (pp. 337-346). New York, NY: Routledge

Seligman, M. E. P., \& Csikszentmihalyi, M. (2000). Positive psychology: An introduction. American Psychologist, 55(1), 5-14.

Shapiro, A., \& Keyes, C. L. M. (2008). Marital status and social well-being: Are the married always better off? Social Indicators Research, 88(2), 329-346. 
Siegrist, J. (1996). Adverse health effects of high-effort/low-reward conditions. Journal of Occupational Health Psychology, 1(1), 27-41.

Springer, K. W., \& Hauser, R. M. (2006). An assessment of the construct validity of Ryff's scales of psychological well-being: Method, mode, and measurement effects. Social Science Research, 35(4), 1080-1102.

Tóth-Király, I., Morin, A. J. S., Bőthe, B., Orosz, G., \& Rigó, A. (2018). Investigating the multidimensionality of need fulfillment: A bifactor exploratory structural equation modeling representation. Structural Equation Modeling, 25(2), 267-286.

van Dierendonck, D. (2004). The construct validity of Ryff's scales of psychological well-being and its extension with spiritual well-being. Personality and Individual Differences, 36(3), 629-643.

Vandenberg, R. J., \& Lance, C. E. (2000). A review and synthesis of the measurement invariance literature: Suggestions, practices, and recommendations for organizational research. Organizational Research Methods, 3(1), 4-69.

Vandenberg, R. J., \& Morelli, N. A. (2016). A contemporary update on testing for measurement equivalence and invariance. In J. P. Meyer (Ed.), Handbook of Employee Commitment (28-42). Cheltenham, UK: Edward Elgar Publishing Limited.

Zinbarg, R. E., Barlow, D. H., \& Brown, T. A. (1997). Hierarchical structure and general factor saturation of the Anxiety Sensitivity Index: Evidence and implications. Psychological Assessment, 9(3), 277-284.

Zinbarg, R. E., Revelle, W., Yovel, I., \& Li, W. (2005). Cronbach's $\alpha$, Revelle's $\beta$, and Mcdonald's $\omega_{\mathrm{H}}$ : Their relations with each other and two alternative conceptualizations of reliability. Psychometrika, 70(1), 1-11. 
Appendix

The Personal Growth and Development Scale

Instructions.

Using the scale provided, click on the most applicable circle for each statement to indicate your level of agreement.

Not at all

1
2
Somewhat

4
Very much so

6

My university experience so far has helped me...

\section{Autonomy:}

1. gain the strength to stand up for what I believe. **

2. feel confident in my decisions. *

3. appreciate the value of setting my own direction in life.

\section{Environmental Mastery}

4. learn how to manage my life more effectively.

5. gain confidence to deal with unforeseen difficulties. *

6. take advantage of opportunities in my surroundings. **

\section{Positive Relations:}

7. learn how to develop meaningful relationships with others. **

8. appreciate others' perspectives on issues.

9. learn to work more effectively with others. *

\section{Self-acceptance:}

10. feel more comfortable with who I am.

11. appreciate my strengths. *

12. feel good about the experiences that have shaped me. **

\section{Purpose in Life:}

13. discover what gives meaning to my life. **

14. identify important goals I want to achieve.

15. get closer to understanding what I want out of life. *

Note. Items were represented without headings (e.g., Autonomy) and in a randomized order.

Items indicated with an ** are recommended for a short, 5-item version of the PGDS while items indicated with an * are recommended, in addition to items included in the 5 -item version, for the 10 -item version. 
Table 1: Definitions of Personal Growth and Development Across Content Domains

\begin{tabular}{ll}
\hline \multicolumn{1}{c}{ Content Domain } & \multicolumn{1}{c}{ Definition } \\
\hline Autonomy & $\begin{array}{l}\text { Perceived enhancement of one's sense of having and being guided by internal standards, and the ability to resist } \\
\text { social pressures to feel, think, or behave in ways that are contrary to those standards. } \\
\text { Environmental Mastery }\end{array}$ \\
Positive Relations & $\begin{array}{l}\text { Perceived enhancement of one's ability to manage challenges in the environment, and to recognize or create } \\
\text { relationships, and to develop empathy, affection and intimacy in these relationships. }\end{array}$ \\
Self-Acceptance & $\begin{array}{l}\text { Perceived enhancement in the recognition and appreciation of one's true self and of the experiences involved in } \\
\text { one's self development. }\end{array}$ \\
Purpose in Life & Perceived enhancement of one's sense of direction and recognition of meaning and purpose in life.
\end{tabular}


Table 2: Standardized Factor Loadings ( $\lambda$ ) and Uniquenesses ( $\delta$ ) for 1-factor CFA for Samples 1-3

\begin{tabular}{|c|c|c|c|c|c|c|c|c|}
\hline \multirow[b]{2}{*}{ Items } & \multicolumn{2}{|c|}{ Sample 1} & \multicolumn{2}{|c|}{ Sample 2} & \multicolumn{2}{|c|}{ Sample 3 T1 } & \multicolumn{2}{|c|}{ Sample 3 T2 } \\
\hline & $\lambda$ & $\delta$ & $\lambda$ & $\delta$ & $\lambda$ & $\delta$ & $\lambda$ & $\delta$ \\
\hline AU1 & $.786^{*}$ & $.383 *$ & $.791 *$ & $.515^{*}$ & $.696^{*}$ & $.515^{*}$ & $.711 *$ & $.495 *$ \\
\hline AU2 & $.779 *$ & $.393^{*}$ & $.792 *$ & $.470 *$ & $.728 *$ & $.470 *$ & $.765^{*}$ & $.414^{*}$ \\
\hline AU3 & $.732 *$ & $.465^{*}$ & $.761 *$ & $.426 *$ & $.758 *$ & $.426^{*}$ & $.674 *$ & $.545^{*}$ \\
\hline EM4 & $.661 *$ & $.563 *$ & $.797 *$ & $.667 *$ & $.577 *$ & $.667 *$ & $.676^{*}$ & $.543 *$ \\
\hline EM5 & $.769 *$ & $.408 *$ & $.791 *$ & $.641 *$ & $.599 *$ & $.641 *$ & $.679 *$ & $.539 *$ \\
\hline EM6 & $.741^{*}$ & $.450 *$ & $.796^{*}$ & $.610^{*}$ & $.624^{*}$ & $.610^{*}$ & $.608 *$ & $.631 *$ \\
\hline PR7 & $.773 *$ & $.403 *$ & $.798 *$ & $.573 *$ & $.654^{*}$ & $.573 *$ & $.588^{*}$ & $.655^{*}$ \\
\hline PR8 & $.679 *$ & $.540 *$ & $.777 *$ & $.810^{*}$ & $.436^{*}$ & $.810^{*}$ & $.524 *$ & $.726^{*}$ \\
\hline PR9 & $.681 *$ & $.536^{*}$ & $.710^{*}$ & $.686^{*}$ & $.560 *$ & $.686^{*}$ & $.566^{*}$ & $.680 *$ \\
\hline SA 10 & $.796 *$ & $.367 *$ & $.833 *$ & $.574 *$ & $.652 *$ & $.574 *$ & $.734^{*}$ & $.462 *$ \\
\hline SA11 & $.799 *$ & $.362 *$ & $.815^{*}$ & $.535^{*}$ & $.682 *$ & $.535^{*}$ & $.729 *$ & $.468 *$ \\
\hline SA12 & $.771 *$ & $.405^{*}$ & $.873 *$ & $.501 *$ & $.706^{*}$ & $.501 *$ & $.766^{*}$ & $.414^{*}$ \\
\hline SP13 & $.742 *$ & $.449 *$ & $.748 *$ & $.595^{*}$ & $.642 *$ & $.595^{*}$ & $.684 *$ & $.533 *$ \\
\hline SP14 & $.588^{*}$ & $.655^{*}$ & $.765^{*}$ & $.597 *$ & $.635^{*}$ & $.597 *$ & $.648^{*}$ & $.580 *$ \\
\hline SP15 & $.695^{*}$ & $.517^{*}$ & $.766^{*}$ & $.588^{*}$ & $.642 *$ & $.588^{*}$ & $.669^{*}$ & $.553^{*}$ \\
\hline$\omega$ & .72 & & .64 & & .54 & & .60 & \\
\hline
\end{tabular}

Note. $\lambda=$ standardized loading on matching factor; $\delta=$ uniqueness; AU = Autonomy; EM = Environmental Mastery; PR $=$ Positive Relations; $\mathrm{SA}=$ Self-

Acceptance; $\mathrm{SP}=$ Sense of Purpose; $\omega=$ model-based coefficient of reliability based on all sources of common variance (omega). ${ }^{*} p<.001$. 
Table 3: Goodness-of-Fit Statistics and Information Criteria for Measurement Invariance Tests

\begin{tabular}{|c|c|c|c|c|c|c|}
\hline Model & $\chi^{2}, d f$ & $C F I$ & RMSEA [90\% CI] & $\Delta \chi^{2}, d f$ & $\triangle C F I$ & $\triangle R M S E A$ \\
\hline \multicolumn{7}{|l|}{ Sample 1-Sample 3 T2 } \\
\hline 1. Configural Invariance & $422.213,182$ & .931 & $.065[.057, .074]$ & - & - & - \\
\hline 2. Metric Invariance & $448.091,195$ & .927 & $.065[.057, .073]$ & $24.891 *, 13$ & -.004 & .000 \\
\hline 3. Scalar Invariance & $528.109,209$ & .908 & $.070[.063, .078]$ & $98.475 * * *, 14$ & -.019 & .005 \\
\hline \multicolumn{7}{|l|}{ Sample 3 T1-Sample 3 T2 } \\
\hline 1. Configural Invariance & $644.404,391$ & .944 & $.041[.036, .047]$ & - & - & - \\
\hline 2. Metric Invariance & $664.773,404$ & .942 & $.041[.036, .047]$ & $20.288,13$ & -.002 & .000 \\
\hline 3. Scalar Invariance & $709.973,418$ & .935 & $.043[.038, .048]$ & $49.491 * * *, 14$ & -.007 & .002 \\
\hline \multicolumn{7}{|l|}{ Sample 2-Sample 1} \\
\hline 1. Configural Invariance & $655.371,182$ & .911 & $.086[.079, .093]$ & - & - & - \\
\hline 2. Metric Invariance & $659.559,195$ & .912 & $.082[.075, .089]$ & $-11.816,13$ & .001 & -.004 \\
\hline 3. Scalar Invariance & $835.493,209$ & .882 & $.092[.085, .099]$ & $232.790^{* * *}, 14$ & -.030 & .010 \\
\hline
\end{tabular}

Note. $\chi^{2}$ scaled chi-square test of exact fit; $\mathrm{df}=$ degrees of freedom; $\mathrm{CFI}=$ comparative fit index; RMSEA = root mean square error of approximation; $\mathrm{CI}=$ confidence interval; $\Delta \chi^{2}$, = chi-square difference test with previous model; $\Delta \mathrm{CFI}=$ change in CFI from previous model; $\Delta$ RMSEA $=$ change in RMSEA from previous model. All models estimated using MLR. $* p<.05, * p<.01, * * * p<.001$. 
Table 4: Sample 1 Descriptive Statistics, Reliabilities, and Correlations between PGDS-E and Other Study Variables

\begin{tabular}{|c|c|c|c|c|c|c|c|c|c|c|c|c|c|}
\hline & $M$ & $S D$ & 1. & 2. & 3. & 4. & 5. & 6. & 7. & 8. & 9. & 10. & 11. \\
\hline 1. PGDS-E & 5.16 & 1.04 & $(.95)$ & & & & & & & & & & \\
\hline 2. SPWB & 4.26 & .59 & $.53^{* *}$ & $(.83)$ & & & & & & & & & \\
\hline 3. BNS-G & 5.18 & .77 & $.62^{* *}$ & $.65^{* *}$ & $(.86)$ & & & & & & & & \\
\hline 4. BNS-G AU & 5.16 & 1.05 & $.52 * *$ & $.62^{* *}$ & $.79 * *$ & (.66) & & & & & & & \\
\hline 5. BNS-G CO & 5.66 & .87 & $.63^{* *}$ & $.60^{* *}$ & $.86^{* *}$ & $.64 * *$ & (.67) & & & & & & \\
\hline 6. BNS-G RE & 4.62 & .89 & $.42 * *$ & $.46^{* *}$ & $.85^{* *}$ & $.51 * *$ & $.52 * *$ & $(.82)$ & & & & & \\
\hline 7. MBI & 4.06 & 1.16 & $-.47 * *$ & $-.53 * *$ & $-.49 * *$ & $-.42 * *$ & $-.28 * *$ & $-.57 * *$ & $(.93)$ & & & & \\
\hline 8. UWES & 3.12 & .87 & $.56^{* *}$ & $.46 * *$ & $.44 * *$ & $.44 * *$ & $.22 * *$ & $.50 * *$ & $-.57 * *$ & $(.92)$ & & & \\
\hline 9. Pos Aff & 3.39 & .74 & $.66^{* *}$ & $.54 * *$ & $.55^{* *}$ & $.46^{* *}$ & $.61 * *$ & $.34 * *$ & $-.58 * *$ & $.69 * *$ & $(.90)$ & & \\
\hline 10. Neg Aff & 2.65 & .82 & $-.34 * *$ & $-.46^{* *}$ & $-.47 * *$ & $-.42 * *$ & $-.48 * *$ & $-.30 * *$ & $.58 * *$ & $-.28 * *$ & $-.25 * *$ & $(.88)$ & \\
\hline 11. PHQ & 3.37 & 1.11 & $-.14 * *$ & $-.23 * *$ & $-.19 * *$ & $-.19 * *$ & $-.26 * *$ & -.05 & $.42 * *$ & $-.20 * *$ & $-.16^{*}$ & $.53 * *$ & (.90) \\
\hline
\end{tabular}

Note. $N=232-241 . * p<.05 ; * * p<.01$. PGDS-E = Personal Growth and Develop Scale Education Version; SPWB = composite Scales of Psychological WellBeing; BNS-G = Basic Needs Satisfaction in General Composite; BNS-G AU = Basic Needs Satisfaction in General Autonomy Subscale; BNS-G CO = Basic Needs Satisfaction in General Competence Subscale; BNS-G RE = Basic Needs Satisfaction in General Relatedness Subscale; MBI = student version of the Maslach Burnout Inventory; UWES = student version of the Utrecht Work Engagement Survey; Pos Aff = positive dimension of the Positive and Negative Affect Schedule; Neg Aff = negative dimension of the Positive and Negative Affect Schedule; PHQ = Physical Health Questionnaire. 
Table 5: Sample 2 Descriptive Statistics, Reliabilities, and Correlations between PGDS-W and Outcomes

\begin{tabular}{|c|c|c|c|c|c|c|c|c|c|c|c|c|c|}
\hline & $M$ & $S D$ & 1. & 2. & 3. & 4. & 5. & 6. & 7. & 8. & 9. & 10. & 11. \\
\hline 1. PGDS-W & 4.60 & 1.39 & $(.96)$ & & & & & & & & & & \\
\hline 2. BNS-W & 4.87 & 1.06 & $.59 * *$ & $(.92)$ & & & & & & & & & \\
\hline 3. BNS-W AU & 4.55 & 1.21 & $.52 * *$ & $.88^{* *}$ & $(.84)$ & & & & & & & & \\
\hline 4. BNS-W CO & 5.21 & 1.16 & $.53 * *$ & $.87 * *$ & $.65^{* *}$ & $(.79)$ & & & & & & & \\
\hline 5. BNS-W RE & 4.90 & 1.24 & $.50 * *$ & $.89 * *$ & $.64 * *$ & $.67 * *$ & $(.86)$ & & & & & & \\
\hline 6. SWL & 4.51 & 1.61 & $.47 * *$ & $.47 * *$ & $.47 * *$ & $.39 * *$ & $.38 * *$ & $(.94)$ & & & & & \\
\hline 7. PHQ & 2.65 & 1.04 & $-.16 * *$ & $-.39 * *$ & $-.40 * *$ & $-.34 * *$ & $-.30 * *$ & $-.33 * *$ & $(.92)$ & & & & \\
\hline 8. IM & 4.34 & 1.77 & $.69 * *$ & $.71 * *$ & $.66 * *$ & $.61 * *$ & $.59 * *$ & $.51 * *$ & $-.28 * *$ & $(.92)$ & & & \\
\hline 9. ID & 5.21 & 1.49 & $.58 * *$ & $.66^{* *}$ & $.56^{* *}$ & $.62 * *$ & $.53 * *$ & $.37 * *$ & $-.22 * *$ & $.66^{* *}$ & $(.86)$ & & \\
\hline 10. ExSoc & 4.22 & 1.40 & $.24 * *$ & $.09 *$ & .02 & $.10^{*}$ & $.12 * *$ & .01 & .09 & $.14^{* *}$ & $.17 * *$ & $(.74)$ & \\
\hline 11. ExMat & 4.65 & 1.35 & $.10^{*}$ & .09 & -.04 & $.16^{*}$ & $.12 *$ & .02 & .03 & .07 & $.11^{*}$ & $.48 * *$ & (.64) \\
\hline
\end{tabular}

Note. $N=443-468 . * p<.05 ; * * p<.01$. PGDS-W = Personal Growth and Development Scale Work Version; BNS-W = Basic Needs Satisfaction at Work

Composite; BNS-W AU = Basic Needs Satisfaction at Work Autonomy Subscale; BNS-W CO = Basic Needs Satisfaction at Work Competence Subscale; BNS-

W RE = Basic Needs Satisfaction at Work Relatedness Subscale; SWL = Satisfaction with Life; PHQ = Physical Health Questionnaire; IM = Intrinsic

Motivation; ID = Identified Regulation; ExSoc = Extrinsic Regulation-Social; ExMat = Extrinsic Regulation-Material.

Table 6: Sample 3 Descriptive Statistics, Reliabilities, and Correlations between PGDS-E and Outcomes for Time 1 and Time 2

\begin{tabular}{|c|c|c|c|c|c|c|c|c|c|c|c|c|c|c|}
\hline & $M_{T 1}$ & $S D_{T 1}$ & $M_{T 2}$ & $S D_{T 2}$ & 1. & 2. & 3. & 4. & 5. & 6. & 7. & 8. & 9. & 10. \\
\hline 1. PGDS-E & 4.85 & 1.00 & 5.12 & 1.00 & $(.91 / .92)$ & $.70 * *$ & $.67 * *$ & $.54 * *$ & $.64 * *$ & $.56^{* *}$ & $.54 * *$ & $.52 * *$ & $-.17 * *$ & $.13^{*}$ \\
\hline 2. SPWB & 4.28 & .58 & 4.32 & .62 & $.64 * *$ & $(.94 / .95)$ & $.85^{* *}$ & $.74 * *$ & $.74 * *$ & $.71 * *$ & $.49 * *$ & $.51 * *$ & $-.39 * *$ & .10 \\
\hline 3. BNS-G & 5.06 & .79 & 5.10 & .79 & $.68 * *$ & $.82 * *$ & $(.88 / .88)$ & $.87 * *$ & $.84 * *$ & $.86^{* *}$ & $.51 * *$ & $.52 * *$ & $-.32 * *$ & .08 \\
\hline 4. BNS-G AU & 4.79 & .87 & .487 & .87 & $.55^{* *}$ & $.70 * *$ & $.85^{* *}$ & $(.69 / .71)$ & $.64 * *$ & $.63 * *$ & $.44 * *$ & $.43 * *$ & $-.35 * *$ & $.11 *$ \\
\hline 5. BNS-G CO & 4.71 & .98 & 4.72 & 1.01 & $.61 * *$ & $.67 * *$ & $.82 * *$ & $.58 * *$ & $(.71 / .72)$ & $.55 * *$ & $.54 * *$ & $.51 * *$ & $-.31 * *$ & .08 \\
\hline 6. BNS-G RE & 5.56 & .94 & 5.60 & .90 & $.58 * *$ & $.72 * *$ & $.88 * *$ & $.62 * *$ & $.56^{* *}$ & $(.83 / .83)$ & $.35^{* *}$ & $.42 * *$ & $-.19 * *$ & $.20 * *$ \\
\hline 7. IM & 5.19 & 1.27 & 5.07 & 1.30 & $.43 * *$ & $.37 * *$ & $.36 * *$ & $.30 * *$ & $.35 * *$ & $.28 * *$ & $(.93 / .93)$ & $.67 * *$ & $-.21 * *$ & .09 \\
\hline 8. ID & 5.77 & .95 & 5.68 & 1.00 & $.41 * *$ & $.42 * *$ & $.40 * *$ & $.33 * *$ & $.31 * *$ & $.37 * *$ & $.58 * *$ & $(.86 / .87)$ & $-.13 *$ & $.23 * *$ \\
\hline 9. ExSoc & 4.27 & 1.53 & 4.42 & 1.48 & -.10 & $-.30 * *$ & $-.23 * *$ & $-.30 * *$ & $-.19 * *$ & $-.12 * *$ & $-.11 *$ & -.09 & $(.82 / .82)$ & $.27 * *$ \\
\hline 10. ExMat & 6.56 & .55 & 6.35 & .67 & $.20 * *$ & $.18^{* *}$ & $.25 * *$ & $.18 * *$ & $.14 * *$ & $.30 * *$ & $.13^{* *}$ & $.36^{* *}$ & $.16^{* *}$ & $(.67 / .58)$ \\
\hline
\end{tabular}

Note. $N=374-377 .{ }^{*} p<.05 ; * *<.01$. Correlations for Time 1 are presented below the diagonal. Correlations for Time 2 are presented above the diagonal.

Reliabilities are given in the diagonal for Time 1 and Time 2 respectively. PGDS-E = Personal Growth and Develop Scale Education Version; SPWB = composite Scales of Personal Well-Being; BNS-G = Basic Needs Satisfaction in General Composite; BNS-G AU = Basic Needs Satisfaction in General

Autonomy Subscale; BNS-G CO = Basic Needs Satisfaction in General Competence Subscale; BNS-G RE = Basic Needs Satisfaction in General Relatedness

Subscale; IM = Intrinsic Motivation; ID = Identified Regulation; ExSoc = Extrinsic Regulation-Social; ExMat = Extrinsic Regulation-Material. 
Table 7: Sample 3 Time-Lagged Correlations

\begin{tabular}{|c|c|c|c|c|c|c|c|c|c|c|}
\hline & 1. $\mathrm{T} 2$ & 2. $\mathrm{T} 2$ & 3. T2 & 4. T2 & $5 . \mathrm{T} 2$ & 6. T2 & 7. T2 & 8. T2 & 9. $\mathrm{T} 2$ & 10. T2 \\
\hline 1. PGDS-E $\mathrm{E}_{\mathrm{T} 1}$ & $.65 * *$ & $.52 * *$ & $.52 * *$ & $.41 * *$ & $.48 * *$ & $.44 * *$ & $.38 * *$ & $.33 * *$ & $-.18 * *$ & .01 \\
\hline 2. $\mathrm{SPWB}_{\mathrm{T} 1}$ & $.58 * *$ & $.84 * *$ & $.82 * *$ & $.70 * *$ & $.67 * *$ & $.72 * *$ & $.37 * *$ & $.42 * *$ & $-.30 * *$ & $.18 * *$ \\
\hline 3. BNS-G $\mathrm{G}_{\mathrm{T} 1}$ & $.54 * *$ & $.71 * *$ & $.76 * *$ & $.85^{* *}$ & $.82 * *$ & $.88 * *$ & $.36 * *$ & $.40 * *$ & $-.23 * *$ & $.25 * *$ \\
\hline 4. BNS-G AU $\mathrm{AU}_{\mathrm{T} 1}$ & $.46^{* *}$ & $.65^{* *}$ & $.68 * *$ & $.68 * *$ & $.58 * *$ & $.62 * *$ & $.30 * *$ & $.33 * *$ & $-.30 * *$ & $.18 * *$ \\
\hline 5. BNS-G CO $\mathrm{T}_{\mathrm{T} 1}$ & $.44 * *$ & $.54 * *$ & $.57 * *$ & $.44 * *$ & $.66 * *$ & $.56^{* *}$ & $.35 * *$ & $.31 * *$ & $-.19 * *$ & $.14 * *$ \\
\hline 6. BNS-G RE ${ }_{\mathrm{T} 1}$ & $.48 * *$ & $.62 * *$ & $.69 * *$ & $.51 * *$ & $.50 * *$ & $.74 * *$ & $.28 * *$ & $.37 * *$ & $-.16 * *$ & $.30 * *$ \\
\hline 7. $\mathrm{IM}_{\mathrm{T} 1}$ & $.35 * *$ & $.34 * *$ & $.32 * *$ & $.29 * *$ & $.35 * *$ & $.20 * *$ & $.64 * *$ & $.58 * *$ & $-.11 * *$ & $.13 * *$ \\
\hline 8. $\mathrm{ID}_{\mathrm{T} 1}$ & $.41 * *$ & $.42 * *$ & $.40 * *$ & $.30 * *$ & $.38 * *$ & $.34 * *$ & $.49 * *$ & $.66 * *$ & -.09 & $.36 * *$ \\
\hline 9. ExSoc $_{\mathrm{T} 1}$ & $-.13 * *$ & $-.30 * *$ & $-.26 * *$ & $-.25 * *$ & $-.24 * *$ & $-.18 * *$ & $-.13 *$ & $-.12 *$ & $.61 * *$ & $.16 * *$ \\
\hline 10. ExMat ${ }_{\mathrm{T} 1}$ & $.13 * *$ & $.17 * *$ & $.18^{* *}$ & $.11^{* *}$ & $.12 * *$ & $.23 * *$ & .09 & $.23 * *$ & $.10^{*}$ & $.38 * *$ \\
\hline
\end{tabular}

Note. $N=374-377 . * p<.05 ; * * p<.01$. Measures collected at Time 1 are presented vertically, while the corresponding measures collected at Time 2 are presented horizontally. Test-retest reliability is presented in bold in the diagonal. PGDS-E = Personal Growth and Develop Scale Education Version; SPWB = composite Scales of Personal Well-Being; BNS-G = Basic Needs Satisfaction in General Composite; BNS-G AU = Basic Needs Satisfaction in General Autonomy Subscale; BNS-G CO = Basic Needs Satisfaction in General Competence Subscale; BNS-G RE = Basic Needs Satisfaction in General Relatedness Subscale; IM = Intrinsic Motivation; ID = Identified Regulation; ExSoc = Extrinsic Regulation-Social; ExMat = Extrinsic Regulation-Material.

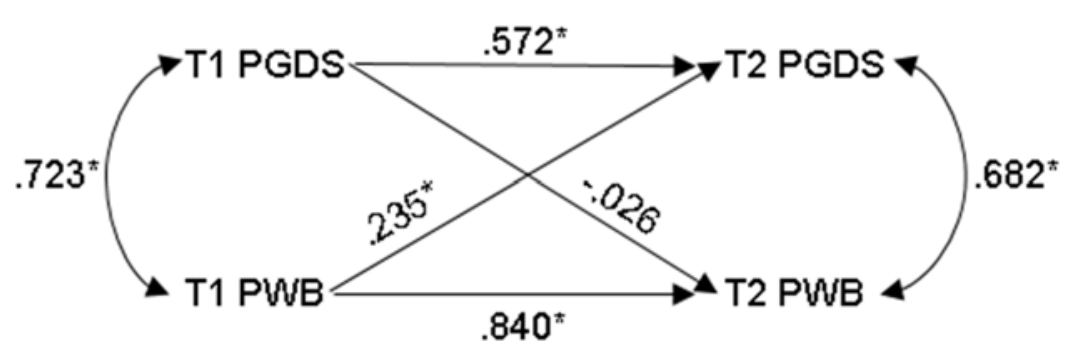

Figure 1. Cross-lagged model of students' personal growth and development (PGDS) and psychological well-being (PWB) across two time points. * $p<.001$. 
Online Supplemental Materials for

Measuring Personal Growth and Development in Context: Evidence of Validity in Educational and Work Settings

Table S1: Sample 1 Descriptive Statistics, Reliabilities, and Correlations between PGDS-E (15, 10, and 5-item) and Other Study Variables

\begin{tabular}{|c|c|c|c|c|c|}
\hline & $M$ & $S D$ & 15-item & 10-item & 5-item \\
\hline 1. PGDS-E (15-item) & 5.16 & 1.04 & $(.95)$ & & \\
\hline 2. PGDS-E (10-item) & 5.07 & 1.10 & $.99 * *$ & $(.93)$ & \\
\hline 3. PGDS-E (5-item) & 5.05 & 1.17 & $.96 * *$ & $.97 * *$ & $(.87)$ \\
\hline 4. SPWB & 4.26 & .59 & $.53 * *$ & $.51 * *$ & $.51 * *$ \\
\hline 5. BNS-G & 5.18 & .77 & $.62 * *$ & $.61 * *$ & $.59 * *$ \\
\hline 6. BNS-G AU & 5.16 & 1.05 & $.52 * *$ & $.52 * *$ & $.49 * *$ \\
\hline 7. BNS-G CO & 5.66 & .87 & $.63 * *$ & $.63 * *$ & $.59 * *$ \\
\hline 8. BNS-G RE & 4.62 & .89 & $.42 * *$ & $.41 * *$ & $.41 * *$ \\
\hline 9. MBI & 4.06 & 1.16 & $-.47 * *$ & $-.46 * *$ & $-.45 * *$ \\
\hline 10. UWES & 3.12 & .87 & $.56^{* *}$ & $.54 * *$ & $.53 * *$ \\
\hline 11. Pos Aff & 3.39 & .74 & $.66^{* *}$ & $.66^{* *}$ & $.66^{* *}$ \\
\hline 12. Neg Aff & 2.65 & .82 & $-.34 * *$ & $-.34 * *$ & $-.32 * *$ \\
\hline 13. PHQ & 3.37 & 1.11 & $-.14^{*}$ & $-.14^{*}$ & $-.14 *$ \\
\hline
\end{tabular}

Note. $N=232-241 .{ }^{*} p<.05 ; * * p .01$. PGDS-E = Personal Growth and Develop Scale Education Version; SPWB = composite Scales of Psychological WellBeing; BNS-G = Basic Needs Satisfaction in General Composite; BNS-G AU = Basic Needs Satisfaction in General Autonomy Subscale; BNS-G CO = Basic Needs Satisfaction in General Competence Subscale; BNS-G RE = Basic Needs Satisfaction in General Relatedness Subscale; MBI = student version of the Maslach Burnout Inventory; UWES = student version of the Utrecht Work Engagement Survey; Pos Aff = positive dimension of the Positive and Negative Affect Schedule; Neg Aff = negative dimension of the Positive and Negative Affect Schedule; PHQ = Physical Health Questionnaire 
Table S2: Sample 2 Descriptive Statistics, Reliabilities, and Correlations between PGDS-W (15, 10, and 5-item) and Other Study Variables

\begin{tabular}{|c|c|c|c|c|c|}
\hline & $M$ & $S D$ & 15-item. & 10 -item & 5-item \\
\hline 1. PGDS-W (15-item) & 4.60 & 1.39 & $(.96)$ & & \\
\hline 2. PGDS-W (10-item) & 4.63 & 1.39 & $.99 * *$ & $(.94)$ & \\
\hline 3. PGDS-W (5-item) & 4.39 & 1.51 & $.96^{* *}$ & $.97 * *$ & $(.90)$ \\
\hline 5. BNS-W & 4.87 & 1.06 & $.59 * *$ & $.60^{* *}$ & $.54 * *$ \\
\hline 6. BNS-W AU & 4.55 & 1.21 & $.52^{* *}$ & $.53^{* *}$ & $.50^{* *}$ \\
\hline 7. BNS-W CO & 5.21 & 1.16 & $.53^{* *}$ & $.54^{* *}$ & $.46^{* *}$ \\
\hline 8. BNS-W RE & 4.90 & 1.24 & $.50^{* *}$ & $.51^{* *}$ & $.47 * *$ \\
\hline 9. SWL & 4.51 & 1.61 & $.47 * *$ & $.48^{* *}$ & $.47 * *$ \\
\hline 10. PHQ & 2.65 & 1.04 & $-.16^{* *}$ & $-.16^{* *}$ & $-.15^{* *}$ \\
\hline 11. IM & 4.34 & 1.77 & $.69 * *$ & $.69 * *$ & $.68 * *$ \\
\hline 12. ID & 5.21 & 1.49 & $.58^{* *}$ & $.58 * *$ & $.53 * *$ \\
\hline 13. ExSoc & 4.22 & 1.40 & $.24 * *$ & $.24 * *$ & $.23 * *$ \\
\hline 14. ExMat & 4.65 & 1.35 & $.10^{*}$ & $.11^{*}$ & .06 \\
\hline
\end{tabular}

Note. $N=443-468 .{ }^{*} p<.05 ; * * p<.01$. PGDS-W $=$ Personal Growth and Development Scale Work Version; BNS-W = Basic Needs Satisfaction at Work

Composite; BNS-W AU = Basic Needs Satisfaction at Work Autonomy Subscale; BNS-W CO = Basic Needs Satisfaction at Work Competence Subscale; BNS-

W RE $=$ Basic Needs Satisfaction at Work Relatedness Subscale; SWL = Satisfaction with Life; PHQ = Physical Health Questionnaire; IM = Intrinsic

Motivation; ID = Identified Regulation; ExSoc = Extrinsic Regulation-Social; ExMat = Extrinsic Regulation-Material. 
Table S3: Sample 3 Descriptive Statistics, Reliabilities, and Correlations between PGDS-E (15, 10, and 5-item) and Other Study Variables

\begin{tabular}{|c|c|c|c|c|c|c|c|c|}
\hline & $M_{T 1}$ & $S D_{T 1}$ & T1 15-item & T1 10-item & T1 5-item & T2 15-item & T2 10-item & T2 5-item \\
\hline 1. PGDS-E (15-item) & 4.85 & 1.00 & $(.91)$ & & & $(.92)$ & & \\
\hline 2. PGDS-E (10-item) & 4.73 & 1.07 & $.98 * *$ & $(.88)$ & & $.99 * *$ & $(.89)$ & \\
\hline 3. PGDS-E (5-item) & 4.67 & 1.16 & $.93 * *$ & $.95 * *$ & $(.80)$ & $.94 * *$ & $.95 * *$ & $(.80)$ \\
\hline 4. SPWB & 4.28 & .58 & $.64 * *$ & $.62 * *$ & $.58 * *$ & $.70 * *$ & $.69 * *$ & $.65 * *$ \\
\hline 5. BNS-G & 5.06 & .79 & $.68 * *$ & $.66^{* *}$ & $.62 * *$ & $.67 * *$ & $.66^{* *}$ & $.63 * *$ \\
\hline 6. BNS-G AU & 4.79 & .87 & $.55 * *$ & $.53 * *$ & $.50 * *$ & $.54 * *$ & $.53 * *$ & $.51 * *$ \\
\hline 7. BNS-G CO & 4.71 & .98 & $.61 * *$ & $.59 * *$ & $.52 * *$ & $.64 * *$ & $.63 * *$ & $.58 * *$ \\
\hline 8. BNS-G RE & 5.56 & .94 & $.58 * *$ & $.57 * *$ & $.56^{* *}$ & $.56 * *$ & $.55^{* *}$ & $.53 * *$ \\
\hline 9. IM & 5.19 & 1.27 & $.43 * *$ & $.41 * *$ & $.38 * *$ & $.54 * *$ & $.52 * *$ & $.51 * *$ \\
\hline 10. ID & 5.77 & .95 & $.41 * *$ & $.39 * *$ & $.38 * *$ & $.52 * *$ & $.50 * *$ & $.49 * *$ \\
\hline 11. ExSoc & 4.27 & 1.53 & -.10 & -.10 & -.09 & $-.17 * *$ & $-.16^{* *}$ & $-.16^{* *}$ \\
\hline 12. ExMat & 6.56 & .55 & $.20 * *$ & $.17 * *$ & $.16^{* *}$ & $.13 *$ & $.11^{*}$ & .09 \\
\hline
\end{tabular}

Note. $N=374-377 .{ }^{*} p<.05 ; * * p<.01$. All PGDS measures are correlated within time to the respective study covariates. Reliabilities are given in the diagonal. PGDS-E = Personal Growth and Develop Scale Education Version; SPWB = composite Scales of Personal Well-Being; BNS-G = Basic Needs Satisfaction in General Composite; BNS-G AU = Basic Needs Satisfaction in General Autonomy Subscale; BNS-G CO = Basic Needs Satisfaction in General Competence Subscale; BNS-G RE = Basic Needs Satisfaction in General Relatedness Subscale; IM = Intrinsic Motivation; ID = Identified Regulation; ExSoc = Extrinsic Regulation-Social; ExMat = Extrinsic Regulation-Material. 
Table S4: Summary of Standardized Loadings $(\lambda)$ and Uniquenesses $(\delta)$ for 6-Factor Bifactor ESEM of the SPWB in Study 3 at Time 1 and Time 2

\begin{tabular}{|c|c|c|c|c|c|c|c|c|}
\hline \multirow[b]{2}{*}{ Items } & \multicolumn{4}{|c|}{ Time 1} & \multicolumn{4}{|c|}{ Time 2} \\
\hline & Global $\lambda$ & Target $\lambda$ & Cross $\lambda$ Range & $\delta$ & Global $\lambda$ & Target $\lambda$ & $\begin{array}{c}\text { Cross } \lambda \\
\text { Range }\end{array}$ & $\delta$ \\
\hline \multicolumn{9}{|l|}{ Autonomy } \\
\hline AU1 & $.364 *$ & $.561 *$ & $-.162-.004$ & $.508^{*}$ & $.458^{*}$ & $.432 *$ & $-.140-.033$ & $.578 *$ \\
\hline AU7 & $.309 *$ & $.511^{*}$ & $-.193-.145$ & $.582 *$ & $.438^{*}$ & $.452 *$ & $-.161-.065$ & $546^{*}$ \\
\hline AU13R & $.225 *$ & $.398^{*}$ & $-.026-.258$ & $.683 *$ & $.290^{*}$ & $.425^{*}$ & $-.085-.251$ & $.629 *$ \\
\hline AU19 & $.486^{*}$ & $.299 *$ & $-.099-.210$ & $.610^{*}$ & $.647 *$ & $.246^{*}$ & $-.214-.172$ & $.589 *$ \\
\hline AU25R & $.138^{*}$ & $.487 *$ & $-.033-.154$ & $.688^{*}$ & $.232 *$ & $.657^{*}$ & $-.006-.098$ & $.497 *$ \\
\hline AU31 & $.466^{*}$ & $.545^{*}$ & $-.119-.076$ & $.461^{*}$ & $.492 *$ & $.497 *$ & $-.107-.005$ & $.491 *$ \\
\hline AU37R & $.352 *$ & $.485^{*}$ & $-.085-.208$ & $.579 *$ & $.355^{*}$ & $.533^{*}$ & $-.025-.224$ & $.524 *$ \\
\hline AU43R & $.136^{*}$ & $.516^{*}$ & $.019-.208$ & $.621^{*}$ & $.179 *$ & $.542 *$ & $.019-.143$ & $.639 *$ \\
\hline \multirow[t]{2}{*}{ AU49 } & $.452 *$ & $.419^{*}$ & $-.162-.082$ & $.560^{*}$ & $.562 *$ & $.266^{*}$ & $-.202-.202$ & $.565^{*}$ \\
\hline & $M \mathrm{G}|\lambda|=.325$ & $M \mathrm{~T}|\lambda|=.469$ & $M C|\lambda|=.093$ & & $M G|\lambda|=.399$ & $M T|\lambda|=.452$ & $M C|\lambda|=.075$ & \\
\hline \multicolumn{9}{|c|}{ Environmental Mastery } \\
\hline EM2 & $.504 *$ & .066 & $-.052-.144$ & $.715^{*}$ & $.589^{*}$ & .071 & $-.108-.073$ & $.623 *$ \\
\hline EM8R & $.360 *$ & $.514^{*}$ & $.003-.201$ & $.507 *$ & $.371 *$ & $.460^{*}$ & $-.036-.203$ & $.551 *$ \\
\hline EM14R & $.550 *$ & .004 & $-.025-.450$ & $.489 *$ & $.566^{*}$ & -.043 & $-.045-.084$ & $.385^{*}$ \\
\hline EM20 & $.544 *$ & $.456^{*}$ & $-.176-.124$ & $.417^{*}$ & $.306^{*}$ & $.449 *$ & $-.199-.226$ & $.295 *$ \\
\hline EM26R & $.222 *$ & $.577^{*}$ & $.001-173$ & $.565^{*}$ & $.301 *$ & $.549^{*}$ & $-.065-.213$ & $.490 *$ \\
\hline EM32 & $.334 *$ & .177 & $-.151-.017$ & $.813 *$ & $.491 *$ & .143 & $-.170-.056$ & $.846^{*}$ \\
\hline EM38 & $.316^{*}$ & .457 & $-.264-.106$ & $.574 *$ & $.705^{*}$ & $.569^{*}$ & $-.177--.172$ & $.452 *$ \\
\hline EM44R & $.554 *$ & $.390 *$ & $.021-.176$ & $.487^{*}$ & $.632 *$ & $.294 *$ & $.002-.269$ & $.328 *$ \\
\hline \multirow[t]{2}{*}{ EM50 } & $.623 *$ & .109 & $-.125-.123$ & $.567^{*}$ & $.589^{*}$ & $.179^{*}$ & $-.115-.108$ & $.531 *$ \\
\hline & $M \mathrm{G}|\lambda|=.445$ & $M T|\lambda|=.306$ & $M \mathrm{C}|\lambda|=.092$ & & $M \mathrm{G}|\lambda|=.482$ & $M T|\lambda|=.325$ & $M \mathrm{C}|\lambda|=.110$ & \\
\hline \multicolumn{9}{|c|}{ Personal Growth } \\
\hline PG3R & $.246^{*}$ & $.260^{*}$ & $-.084-.044$ & $.592 *$ & $.297 *$ & $.327^{*}$ & $-.132-.067$ & $.782 *$ \\
\hline PG9R & $.214 *$ & $.563^{*}$ & $-.222-.154$ & $.559 *$ & $.202 *$ & $.637^{*}$ & $-.127-.072$ & $.528 *$ \\
\hline PG15 & $.389 *$ & $.316^{*}$ & $-.244-.035$ & $.647^{*}$ & $.454^{*}$ & $.392 *$ & $-.225-.031$ & $.566^{*}$ \\
\hline PG21R & $.536^{*}$ & .176 & $-.098-.279$ & $.543 *$ & $.636^{*}$ & $.136^{*}$ & $-.074-.140$ & $.533 *$ \\
\hline PG27 & $.598 *$ & .056 & $-.233-.167$ & $.521 *$ & $.665^{*}$ & .026 & $-.152-.077$ & $.518 *$ \\
\hline PG33R & $.236^{*}$ & $.464 *$ & $-.115-.207$ & $.655^{*}$ & $.264 *$ & $.404 *$ & $-.058-.212$ & $.696^{*}$ \\
\hline PG39 & $.552 *$ & .173 & $-.202-.131$ & $.573 *$ & $.621 *$ & $.190 *$ & $-.166-.013$ & $.521 *$ \\
\hline PG45R & $.588^{*}$ & $.289 *$ & $-.053-.265$ & $.470^{*}$ & $.628^{*}$ & $.287^{*}$ & $-.035-.269$ & $.433 *$ \\
\hline \multirow[t]{2}{*}{ PG51R } & $.197^{*}$ & $.286^{*}$ & $-.065-.127$ & $.857^{*}$ & $.289^{*}$ & $.314^{*}$ & $-.077-.125$ & $.785^{*}$ \\
\hline & $M G|\lambda|=.395$ & $M \mathrm{~T}|\lambda|=.287$ & $M C|\lambda|=.101$ & & $M \mathrm{G}|\lambda|=.470$ & $M \mathrm{~T}|\lambda|=.298$ & $M C|\lambda|=.080$ & \\
\hline \multicolumn{9}{|c|}{ Positive Relations } \\
\hline PR4 & $.471 *$ & -.146 & $-.300-.057$ & $.592 *$ & $.446^{*}$ & .117 & $-.162-.007$ & $.711 *$ \\
\hline PR10R & $.446^{*}$ & $.496^{*}$ & $-.121-.037$ & $.529 *$ & $.463^{*}$ & $.574 *$ & $-.073-.001$ & $.448 *$ \\
\hline
\end{tabular}




\begin{tabular}{|c|c|c|c|c|c|c|c|c|}
\hline PR16R & $.539 *$ & $.584 *$ & $-.072-.069$ & $.355^{*}$ & $.539 *$ & $.615^{*}$ & $-.009-.132$ & $.302 *$ \\
\hline PR22 & $.463^{*}$ & .008 & $-.204-.050$ & $.717^{*}$ & $.523^{*}$ & .043 & $-.251-.197$ & $.599 *$ \\
\hline PR28R & $.544 *$ & $.467 *$ & $-.095-.108$ & $.458 *$ & $.485^{*}$ & $.543 *$ & $-.062-.100$ & $.448 *$ \\
\hline PR34R & $.554 *$ & $.499 *$ & $-.059-.106$ & $.415^{*}$ & $.489 *$ & $.535^{*}$ & $-.069-.126$ & $.435^{*}$ \\
\hline PR40 & $.439 *$ & -.12 & $-.246-.148$ & $.621 *$ & $.461^{*}$ & .031 & $-.219-.065$ & $.608 *$ \\
\hline PR46R & $.564 *$ & $.362 *$ & $-.135-.066$ & $.518^{*}$ & $.471^{*}$ & $.488^{*}$ & $-.087-.092$ & $.512^{*}$ \\
\hline PR53 & $.448^{*}$ & .149 & $-.160-.006$ & $.721 *$ & $.505^{*}$ & $.263^{*}$ & $-.157-.093$ & $.608 *$ \\
\hline & $M G|\lambda|=.496$ & $M \mathrm{~T}|\lambda|=.315$ & $M C|\lambda|=.093$ & & $M G|\lambda|=.492$ & $M \mathrm{~T}|\lambda|=.387$ & $M C|\lambda|=.091$ & \\
\hline \multicolumn{9}{|c|}{ Purpose in Life } \\
\hline PL5R & .043 & $.419^{*}$ & $-.216-.100$ & $.738 *$ & .048 & $.612 *$ & $-.193-.053$ & $.582 *$ \\
\hline PL11R & $.309 *$ & .278 & $-.071-.203$ & $.720^{*}$ & $.421 *$ & $.392 *$ & $-.052-.109$ & $.633^{*}$ \\
\hline PL17R & $.561 *$ & .127 & $-.051-.188$ & $.623^{*}$ & $.594^{*}$ & .126 & $-.003-.191$ & $.517^{*}$ \\
\hline PL23R & $.515^{*}$ & $.309 *$ & $-.075-.091$ & $.613^{*}$ & $.564 *$ & $.320 *$ & $-.011-.240$ & $.538 *$ \\
\hline PL29R & $.588^{*}$ & $.441 *$ & $-.074-.173$ & $.407^{*}$ & $.624^{*}$ & $.285^{*}$ & $-.041-.127$ & $.493^{*}$ \\
\hline PL35 & $.535^{*}$ & .304 & $-.124-.094$ & $.592 *$ & $.581 *$ & $.354^{*}$ & $-.147-.153$ & $.487^{*}$ \\
\hline PL41 & $.679 *$ & .229 & $-.211-.148$ & $.394 *$ & $.685^{*}$ & $.228 *$ & $-.267-.144$ & $.384^{*}$ \\
\hline PL47 & $.480 *$ & $.292 *$ & $-.041-.125$ & $.661^{*}$ & $.603^{*}$ & $.199 *$ & $-.099-.101$ & $.569 *$ \\
\hline \multirow[t]{2}{*}{ PL54R } & $.254^{*}$ & .088 & $-.027-.413$ & $.739 *$ & $.326^{*}$ & .021 & $-.072-.318$ & $.779 *$ \\
\hline & $M G|\lambda|=.440$ & $M \mathrm{~T}|\lambda|=.311$ & $M C|\lambda|=.094$ & & $M G|\lambda|=.550$ & $M \mathrm{~T}|\lambda|=.241$ & $M C|\lambda|=.087$ & \\
\hline \multicolumn{9}{|c|}{ Self-Acceptance } \\
\hline SA6 & $.689 *$ & .392 & $-.121-.026$ & $.346^{*}$ & $.694^{*}$ & $.281 *$ & $-.211-.021$ & $.375^{*}$ \\
\hline SA12 & $.712^{*}$ & $.352 *$ & $-.031-.155$ & $.327^{*}$ & $.745^{*}$ & $.318^{*}$ & $-.158-.022$ & $.314^{*}$ \\
\hline SA18R & $.638 *$ & $.273 *$ & $-.018-.210$ & $.446^{*}$ & $.647^{*}$ & $.263^{*}$ & $-.082-.169$ & $.430^{*}$ \\
\hline SA24 & $.674 *$ & .168 & $-.108-.034$ & $.498 *$ & $.706^{*}$ & .137 & $-.209-.003$ & $.421^{*}$ \\
\hline SA30 & $.662 *$ & .195 & $-.135-.030$ & $.502 *$ & $.732 *$ & .130 & $-.071-.061$ & $.436^{*}$ \\
\hline SA36R & $.694 *$ & $.266^{*}$ & $-.064-.180$ & $.409 *$ & $.684 *$ & $.265^{*}$ & $-.039-.156$ & $.424 *$ \\
\hline SA42R & $.568^{*}$ & $.369 *$ & $-.110-.173$ & $.474^{*}$ & $.572 *$ & $.454^{*}$ & $-.038-.161$ & $.417^{*}$ \\
\hline SA48 & $.566^{*}$ & .213 & $-.107-.019$ & $.619^{*}$ & $.595^{*}$ & .031 & $-.158-.047$ & $.612^{*}$ \\
\hline \multirow[t]{2}{*}{ SA55 } & $.467 *$ & .258 & $-.249-.103$ & $.639 *$ & $.454^{*}$ & $.216^{*}$ & $-.356-.026$ & $.609^{*}$ \\
\hline & $M G|\lambda|=.630$ & $M \mathrm{~T}|\lambda|=.276$ & $M \mathrm{C}|\lambda|=.071$ & & $M G|\lambda|=.642$ & $M \mathrm{~T}|\lambda|=.227$ & $M C|\lambda|=.080$ & \\
\hline
\end{tabular}

Note. Global- $\lambda=$ standardized loading on Global factor; Target- $\lambda=$ standardized loading on corresponding specific factor; Cross- $\lambda$ Range $=$ range of standardized loading on non-corresponding specific factors; $\delta=$ uniqueness; $M \mathrm{G}|\lambda|=$ absolute average standardized loading on global factor; $M \mathrm{~T}|\lambda|=$ absolute average standardized loading on corresponding specific factor; $M \mathrm{C}|\lambda|=$ absolute average standardized loading on non-corresponding factors; $\mathrm{AU}=$ Autonomy; EM = Environmental Mastery; PG = Personal Growth; PR = Positive Relations; PL = Purpose in Life; SA = Self-Acceptance; Reverse-coded items end in R. ${ }^{*} p<.05$ 
Table S5: Item Codes for Ryff's (1985) 9-item Scales of Psychological Well-Being

\begin{tabular}{|c|c|}
\hline Item Code & Item Content \\
\hline AU1 & I am not afraid to voice my opinions, even when they are in opposition to the opinions of most people. \\
\hline EM2 & In general, I feel I am in charge of the situation in which I live. \\
\hline PG3R & I am not interested in activities that will expand my horizons. \\
\hline PR4 & Most people see me as loving and affectionate. \\
\hline PL5R & I live life one day at a time and don't really think about the future. \\
\hline SA6 & When I look at the story of my life, I am pleased with how things have turned out. \\
\hline AU7 & My decisions are not usually influenced by what everyone else is doing. \\
\hline EM8R & The demands of everyday life often get me down. \\
\hline PG9R & I don't want to try new ways of doing things--my life is fine the way it is. \\
\hline PR10R & Maintaining close relationships has been difficult and frustrating for me. \\
\hline PL11R & I tend to focus on the present, because the future nearly always brings me problems. \\
\hline SA12 & In general, I feel confident and positive about myself. \\
\hline AU13R & I tend to worry about what other people think of me. \\
\hline EM14R & I do not fit very well with the people and the community around me. \\
\hline PG15 & I think it is important to have new experiences that challenge how you think about yourself and the world. \\
\hline PR16R & I often feel lonely because I have few close friends with whom to share my concerns. \\
\hline PL17R & My daily activities often seem trivial and unimportant to me. \\
\hline SA18R & I feel like many of the people I know have gotten more out of life than I have. \\
\hline AU19 & Being happy with myself is more important to me than having others approve of me. \\
\hline EM20 & I am quite good at managing the many responsibilities of my daily life. \\
\hline PG21R & When I think about it, I haven't really improved much as a person over the years. \\
\hline PR22 & I enjoy personal and mutual conversations with family members or friends. \\
\hline PL23R & I don't have a good sense of what it is I'm trying to accomplish in life. \\
\hline SA24 & I like most aspects of my personality. \\
\hline AU25R & I tend to be influenced by people with strong opinions. \\
\hline
\end{tabular}


EM26R I often feel overwhelmed by my responsibilities

PG27 I have the sense that I have developed a lot as a person over time.

PR28R I don't have many people who want to listen when I need to talk.

PL29R I used to set goals for myself, but that now seems like a waste of time.

SA30 I made some mistakes in the past, but I feel that all in all everything has worked out for the best.

AU31 I have confidence in my opinions, even if they are contrary to the general consensus.

EM32 I generally do a good job of taking care of my personal finances and affairs.

PG33R I do not enjoy being in new situations that require me to change my old familiar ways of doing things.

PR34R It seems to me that most other people have more friends than I do.

PL35 I enjoy making plans for the future and working to make them a reality.

SA36R In many ways, I feel disappointed about my achievements in life.

AU37R It's difficult for me to voice my own opinions on controversial matters.

EM38 I am good at juggling my time so that I can fit everything in that needs to get done.

PG39 For me, life has been a continuous process of learning, changing, and growth.

PR40 People would describe me as a giving person, willing to share my time with others.

PL41 I am an active person in carrying out the plans I set for myself.

SA42R My attitude about myself is probably not as positive as most people feel about themselves.

AU43R I often change my mind about decisions if my friends or family disagree.

EM44R I have difficulty arranging my life in a way that is satisfying to me.

PG45R I gave up trying to make big improvements or changes in my life a long time ago.

PR46R I have not experienced many warm and trusting relationships with others.

PL47 Some people wander aimlessly through life, but I am not one of them.

SA48 The past had its ups and downs, but in general, I wouldn't want to change it.

AU49 I judge myself by what I think is important, not by the values of what others think is important.

EM50 I have been able to build a home and a lifestyle for myself that is much to my liking.

PG51R There is truth to the saying you can't teach an old dog new tricks. 
I know that I can trust my friends, and they know they can trust me.

PL54R I sometimes feel as if I've done all there is to do in life.

SA55

When I compare myself to friends and acquaintances, it makes me feel good about who I am. 